\title{
On the Distinctiveness, Independence, and Time Course of the Brain Responses to Syntactic and Semantic Anomalies
}

\author{
Lee Osterhout \\ Department of Psychology \\ University of Washington \\ Janet Nicol \\ Departments of Psychology and Linguistics \\ University of Arizona
}

\begin{abstract}
We evaluated the distinctiveness, independence, and relative time courses of the event-related brain potentials (ERPs) elicited by syntactically and semantically anomalous words. ERPs were recorded from 13 scalp electrodes while subjects read sentences, some of which contained a selectional restriction violation (semantically anomalous), a verb tense violation (syntactically anomalous), or a doubly anomalous word that violated both selectional restriction and verb tense constraints. Semantic anomalies elicited a monophasic increase in $\mathrm{N} 400$ amplitude, whereas syntactic anomalies elicited a late positive shift with an onset around $500 \mathrm{msec}$ and a duration of several hundred msec. Doubly anomalous words elicited both an increase in
\end{abstract}

Requests for reprints should be addressed to Lee Osterhout, Department of Psychology, Box 351525, University of Washington, Seattle, WA 98195.

A preliminary report of this research was presented at the CUNY Conference on Human Sentence Processing, 1994, New York, in a poster entitled "An event-related brain potential investigation of the temporal course of syntactic and semantic processes", by L. Osterhout, J. Nicol, R. McKinnon, W. Ni, J. Fodor, and S. Crain. We would like to thank Weijia Ni for providing the sentence materials from an experiment conducted at Haskins Laboratories and reported in Fodor, Ni, Crain, and Shankweiler (1996). Thanks also to Rick McKinnon, Mike Bersick, and Judy McLaughlin for running subjects and for comments on previous drafts of this paper, and to Kristin Denham for help with stimulus construction. This research was supported by research grant number R29 DC01947 from the National Institute on Deafness and Other Communication Disorders, National Institutes of Health, awarded to L. O., and by National Multipurpose Research and Training Grant DC01409, also from the National Institute on Deafness and Other Communication Disorders. Please address correspondence concerning this article to Lee Osterhout, Department of Psychology, Box 351525, University of Washington, Seattle, WA, 98195. 
N400 amplitude and a late positive wave, and these effects summated in an approximately (but not perfectly) linear manner. These results are discussed with respect to the hypotheses that syntactic and semantic processes are separable and independent.

\section{INTRODUCTION}

One fundamental claim of current linguistic theories is that syntax (sentence structure) and semantics (sentence meaning) are separable and independent, that is, that the rules of syntax can be specified independently of semantics (Chomsky, 1986). Whether or not this claim is an accurate description of the processes underlying language comprehension has been a matter of debate. A frequent claim within psycholinguistics is that separable, largely independent, and at least partly sequential processes construct distinct syntactic and semantic representations of a sentence (Berwick \& Weinberg, 1984; Ferreira \& Clifton 1986; Forster, 1979; Frazier \& Rayner, 1982). An alternative view is that sentence meaning can be derived directly, without an intervening syntactic level of representation; instead, syntactic and semantic constraints directly and simultaneously influence the message-level representation of the input (JohnsonLaird, 1983; Marslen-Wilson \& Tyler, 1987; McClelland, St. John, \& Taraban, 1989; Taraban \& McClelland, 1988; Tyler \& Marslen-Wilson, 1977). In between these two extremes are models positing separable but interacting syntactic and semantic processes (MacDonald, Pearlmutter, \& Seidenberg, 1994; Trueswell, Tanenhaus, \& Garnsey, 1994).

One means of contrasting these views involves the recording of eventrelated brain potentials (ERPs) elicited during language comprehension (cf. Kutas \& Van Petten, 1994; Osterhout \& Holcomb, 1995). The promise of this approach derives from the fact that ERPs are on-line, continuous measures of the brain's electrical activity that occurs during the process of comprehension. Furthermore, ERPs are multidimensional; they vary in polarity, timing, morphology, and scalp distribution. Assuming that cognitively distinct processes are mediated by neurally distinct brain systems, evidence that events occurring at the syntactic and semantic levels elicit distinct brain responses (i.e., responses that differ in timing, distribution, and/or polarity) could be construed as evidence that separable syntactic and semantic processes exist (Neville, Nicol, Barss, Forster, \& Garrett, 1991; Osterhout \& Holcomb, 1992). Furthermore, evidence that these brain responses are not only distinct but also independent would be consistent with the notion that at least some aspects of syntactic and semantic analysis occur independently.

Particularly relevant to this issue is recent evidence that syntactic and semantic anomalies elicit distinct changes in the ERP (for a review, see 
Osterhout, McLaughlin, \& Bersick, 1997). In a set of pioneering studies, Kutas and Hillyard (1980a, b, c) demonstrated that semantically inappropriate words (e.g., "He spread the warm bread with socks") elicit an enhanced negative wave with an onset around $200 \mathrm{msec}$ and a peak amplitude at about $400 \mathrm{msec}$ (the $N 400$ effect; for a review, see Kutas \& Van Petten, 1994, or Osterhout \& Holcomb, 1995). Subsequent work has shown that N400 amplitude is a function of the degree of semantic congruence between the target word and context, even when the target word is semantically and pragmatically appropriate (Kutas \& Hillyard, 1984).

Efforts to identify a similar ERP correlate of syntactic processing have produced a greater variety of effects. Critically, however, none of these effects resembles the centroparietally distributed N400. At least under certain experimental conditions, a disparate set of syntactic anomalies elicits a large-amplitude, centroparietal positive wave that begins about $500 \mathrm{msec}$ after presentation of the anomalous word and persists for several hundred msec (Coulson, King, \& Kutas, 1998; Friederici, Hahne, \& Mecklinger, 1996; Gunter, Stowe, \& Mulder, 1997; Hagoort, Brown, \& Groothusen, 1993; McKinnon \& Osterhout, 1996; Neville et al., 1991; Osterhout, 1990, 1997; Osterhout \& Holcomb, 1992, 1993; Osterhout, Holcomb, \& Swinney, 1994; Osterhout, McKinnon, Bersick, \& Corey, 1996; Osterhout \& Mobley, 1995). This positive wave, variously labelled the P600 effect (Osterhout \& Holcomb, 1992) and the syntactic positive shift (Hagoort et al., 1993), has been elicited by anomalies involving phrase structure, verb subcategorisation, verb tense, subject-verb number agreement, number and gender pronoun-antecedent agreement, case, and constituent movement. Other ERP responses to syntactic anomalies have been reported. For example, in some reports syntactic anomalies have elicited one or more negative-going effects between about 200 and $500 \mathrm{msec}$. Typically, these negativities are largest over anterior regions and are often largest over anterior sites in the left hemisphere (hence the term Left Anterior Negativity, or LAN; Coulson et al., 1998; Friederici et al., 1996; Gunter et al., 1997; Münte, Heinze, \& Mangun, 1993; Neville et al., 1991; Osterhout \& Holcomb, 1992; Rösler et al. 1993). The LAN effect is often followed by a P600-like positive shift within the same epoch of activity (Friederici et al., 1996; Neville et al., 1991; Rösler, Pütz, Friederici, \& Hahne, 1993; Osterhout \& Holcomb, 1992).

${ }^{1}$ It is clear that this conclusion does not generalise to all experimental conditions. For example, when syntactically anomalous words are presented at the ends of sentences, these words sometimes elicit an N400-like effect and a P600-like effect within the same epoch of activity (Osterhout, 1997). Furthermore, these effects might be less dissociable in languages other than English. For further discussion of these matters, see Osterhout (1997) or the General Discussion. 
Even taking into consideration the variety of ERP responses to syntactic anomalies reported in the literature, it appears that syntactic and semantic anomalies elicit qualitatively distinct brain responses, at least under certain experimental conditions. One caveat associated with this generalisation is that in many studies anomaly type has been confounded with stimulus and task factors. For example, whereas the semantically anomalous words presented in these studies have been members of the open-class vocabulary (e.g., nouns and verbs), syntactically anomalous words usually have been members of the closed class (e.g., auxiliary verbs and infinitival markers). Furthermore, the two categories of anomaly typically have been presented in different sentence contexts and have been tested using a variety of presentation rates and secondary tasks.

The research reported here had three goals. The first goal was to contrast the ERP responses to the two categories of anomaly under conditions in which the word class of the critical word, preceding context, and the task given to the subjects were identical across anomaly type. Such conditions provide the strongest test of the claim that the responses to syntactic and semantic anomalies are qualitatively distinct but have rarely characterised prior work.

The second goal was to determine, to a first approximation, whether the ERP responses to syntactic and semantic anomalies are independent in addition to being qualitatively distinct. We examined this question by determining whether syntactic and semantic anomalies have additive effects on ERPs. This can be accomplished by presenting stimuli that are doubly anomalous, i.e., words that are both syntactically and semantically anomalous. If the two types of anomaly elicit independent effects, then such stimuli should elicit both the "syntactic anomaly" response (P600 effect and anterior negativities) and the "semantic anomaly" response (N400 effect) within the same epoch of activity. Furthermore, in the case of complete independence, the response to the doubly anomalous words would be expected to closely approximate the summation of the response to each type of anomaly in isolation from the other. This prediction follows from Helmholtz's Principle of Superposition, which maintains that electrical fields propagating through a conductive medium summate where they intersect. Evidence of additivity in such situations strongly implies independence of the underlying neural sources (Kutas \& Hillyard, 1980a; Osterhout et al., 1996). However, a failure to find perfect additivity would be less definitive. ERPs primarily reflect the summed, simultaneously occurring postsynaptic activity in large groups of pyramidal neurons in neocortical tissue. This activity would include not just the neural sources of the N400 and P600 effects but also activity from other sources that are active simultaneously and that are consistently time-locked to the onset of the critical word. Thus, even if the N400 and P600 effects summate, this 
summation could be obscured by the influence of other neural sources. The complexity is further increased by the likelihood that the N400 and P600 effects are composites of activity in an indeterminate number of neural sources. In order for a perfectly additive function to be observed, all of these underlying subcomponents would need to add together. (See Osterhout \& Hagoort, 1999, for more discussion of these issues). A less than perfect summation would result if some, but not all, of the neural sources contributing to these two effects summate. In sum, whereas evidence of an additive function strongly implies independence of the N400 and P600 effects, a failure to find perfect additivity would not necessarily indicate that these effects interact.

The third goal was to assess carefully the temporal course of the ERP responses to the two categories of anomaly. Although some behavioural studies have found that syntactic anomalies are detected more rapidly than semantic anomalies (McElree \& Griffith, 1995), other studies have found no difference in the time course of syntactic and semantic anomaly detection (Fodor, Ni, Crain, \& Shankweiler, 1996; Ni, Crain, \& Shankweiler, 1996; Ni, Fodor, Crain, \& Shankweiler, 1998) or even a more rapid behavioural response to semantic/pragmatic anomalies than to syntactic anomalies (Tyler, 1985; Tyler \& Marslen-Wilson, 1977). Assuming that the ERP response to linguistic anomalies is closely timelocked to the detection of the anomalies, ERPs might provide an indication of the relative time course of syntactic and semantic analysis. However, unless one knows with certainty that this assumption is valid, strong inferences about the relative time course of linguistic processes might not be warranted. For example, the P600 typically has an onset around $500 \mathrm{msec}$. This does not necessarily imply that syntactic anomalies are detected $500 \mathrm{msec}$ after presentation of the anomalous word. The P600 might indirectly reflect and be indeterminately removed from the syntactic processes themselves. Nonetheless, the onset of the ERP anomaly response (as indexed by the onset of reliable divergences in the waveforms elicited by anomalous and nonanomalous conditions) provides an upper-bound estimate of the temporal course of anomaly detection (Rugg \& Coles, 1995).

Recently, several ERP experiments have been reported in which syntactic anomalies, semantic anomalies, and doubly anomalous words were presented under conditions similar to those specified above. Unfortunately, several complications prohibit a definitive interpretation of these experiments. Ainsworth-Darnell, Shulman, and Boland (1997) reported that semantically anomalous words elicited an N400 effect, syntactically anomalous words elicited a P600 effect, and doubly anomalous words elicited both an N400 and a P600. However, the waveforms reported by Ainsworth et al. were notably noisy, and clear 
differences existed in the waveforms prior to onset of the critical word. These problems might have reflected the relatively small number of trials (20) per condition and the fact that words from different word classes (prepositions and verbs) immediately preceded onset of the critical words across conditions. ${ }^{2}$ Furthermore, a thorough analysis of the additivity of these effects was not reported. Gunter et al. (1997) reported two experiments. Semantic anomalies elicited an N400 effect and syntactic anomalies elicited a P600 effect (Experiment 1) or a P600 effect plus an earlier anterior negativity (Experiment 2). In Experiment 1, ERPs to the doubly anomalous stimuli approximated the summation of the responses to the syntactic and semantic anomalies in isolation. In Experiment 2 the P600 response to doubly anomalous words was reduced in amplitude, relative to the P600 elicited by syntactic anomalies; furthermore, the anterior negativity and the N400 effect seemed to summate. However, the critical words in both experiments were placed in sentence-final position. This introduces the possibility that the response to the anomaly was at least partially confounded with end-of-sentence wrap-up, decision, and response processes (cf. Osterhout, 1994; Osterhout \& Holcomb, 1995). Especially noteworthy in this regard is evidence that ERPs to sentences containing a syntactic anomaly deviate in at least two ways from those to well-formed controls: the anomalous word elicits a P600like positivity and the nonanomalous sentence-final word elicits an enhanced N400-like effect followed by long-lasting differences between the well-formed and anomalous conditions (Hagoort et al., 1993; McKinnon \& Osterhout, 1996; Osterhout \& Holcomb, 1992, 1993; Osterhout \& Mobley, 1995). Such sentence-ending effects might contaminate the response to the linguistic anomaly when it appears in sentence-final position (cf. Osterhout, 1997).

In summary, the current study was designed to carefully examine the distinctiveness, time course, and independence of the brain responses to sentence-embedded syntactically and semantically anomalous words,

\footnotetext{
${ }^{2}$ In order to compare two waveforms, it is necessary to employ a baseline in which the recorded electrical activity is assumed to be equal across the conditions of the experiment (cf. Garnsey, 1993). The convention is to assume equality within the $100 \mathrm{msec}$ of activity preceding onset of the critical stimulus and to use activity in this window as the baseline. However, in the Ainsworth-Darnell et al. study, choice of a baseline was complicated by the fact that words from different word classes preceded the critical word across conditions. It is known that words from different word classes elicit distinct ERPs (cf. Neville, Mills, \& Lawson, 1992). Hence, one cannot assume that activity was equal across conditions prior to critical word onset. Also, such a design introduces the possibility that substantial differences in brain activity extended into the epoch associated with the critical word, a contamination that is not necessarily removed regardless of the baseline used.
} 
under conditions in which the word class and position of the critical word, preceding and following context, and task factors were held constant across conditions. The purpose of Experiment 1 was to determine whether specific types of syntactic and semantic anomalies elicit qualitatively distinct ERP responses (e.g., the P600 and N400 effects) under such experimental conditions. In Experiment 2, we tested the additivity of these responses by presenting doubly as well singly anomalous words.

\section{EXPERIMENT 1}

\section{Methods}

Subjects. Fifteen undergraduate students ( 9 females and 6 males) participated for course credit or for a small compensation. Subjects ranged in age from 18 to 42 years. All subjects in this experiment and in Experiment 2 were right-handed native English speakers with normal or corrected-to-normal vision.

Stimuli and Procedures. Three versions of 90 sentences were prepared, as exemplified by the first three types of example sentences in Table 1. The entire set of experimental materials is listed in the Appendix. One version was syntactically and semantically well-formed.

TABLE 1

Examples of Experimental Sentences

Nonanomalous controls

The cat won't eat the food that Mary leaves them.

The expensive ointment will cure all known forms of skin disease.

The new fighter planes can $f l y$ faster than anyone had expected.

Syntactically anomalous (verb tense violations)

The cat won't eating the food that Mary leaves them.

The expensive ointment will curing all known forms of skin disease.

The new fighter planes can flying faster than anyone had expected.

Semantically anomalous (selectional restriction violations)

The cat won't bake the food that Mary leaves them.

The expensive ointment will loathe all known forms of skin disease.

The new fighter planes can walk faster than anyone had expected.

Doubly anomalous (verb tense and selectional restriction violations)

The cat won't baking the food that Mary leaves them.

The expensive ointment will loathing all known forms of skin disease.

The new fighter planes can walking faster than anyone had expected. 
The syntactically anomalous version always involved a modal verb followed by a present participle (-ing) form of the verb (e.g., won't baking, verb tense violations). In the semantically anomalous version, the matrix verb appeared in the grammatically appropriate nontensed form but introduced an unsuitable pairing of actions with agents (e.g., catsbake). The unsuitability was often but not always due to a mismatch in animacy between the verb and the subject of the sentence. Such anomalies are referred to in the linguistics literature as selectional restriction violations (Chomsky, 1965). The nonanomalous and semantically anomalous critical words were matched in frequency (nonanomalous: mean $=96$, anomalous: mean $=70, P 4$ 0.2; Kucera \& Francis, 1967 ) and length in letters (nonanomalous: mean $=4.94$, anomalous $=$ $4.52, P 40.3$ ). The properly tensed versions of each word were used to match for length and frequency.

These materials were then used to create three stimulus lists. Each list contained 30 exemplars of each of the three experimental sentence types. Items were counterbalanced such that only one version of each sentence was presented on a given list. Ninety filler sentences were also added to each list. (These sentences were part of another experiment not reported here.) Thirty of these were syntactically and semantically wellformed simple active structures (e.g., "The car raced around the speedway and crashed."); 30 contained a semantically anomalous word in sentence-final position (e.g., "The car raced around the speedway and sneezed."); and 30 contained a reduced relative clause (e.g., "The car raced around the speedway crashed."). These latter sentences are technically well-formed but are often judged to be unacceptable. Thus, each subject saw a total of 180 sentences. Sixty of these sentences were well-formed; 30 were syntactically anomalous; 60 contained a semantically anomalous word; and 30 were technically well-formed but often judged to be unacceptable.

Each trial consisted of the following events: A fixation cross appeared for $500 \mathrm{msec}$, after which a sentence was presented in a word-by-word manner, with each word appearing on the centre of the screen for $300 \mathrm{msec}$. A blank-screen interval of $350 \mathrm{msec}$ separated words. Sentence-ending words appeared with a full stop. A 1450-msec blank-screen interval followed each sentence, after which a prompt appeared asking subjects to decide if the preceding sentence was "acceptable" or "unacceptable". Acceptable sentences were defined as those that were semantically coherent and grammatically well-formed. Subjects responded by pressing one of two buttons, which were counterbalanced (left and right) across subjects. Subjects were tested in one session that lasted approximately two hours, during which they were seated in a comfortable chair located in an isolated room. 
Data acquisition and analysis. Continuous EEG was recorded from 13 scalp sites using tin electrodes attached to an elastic cap (Electrocap International). Electrode placement included International 10-20 system locations (Jasper, 1958) over homologous positions over the left and right occipital $(\mathrm{O} 1, \mathrm{O} 2)$ and frontal $(\mathrm{F} 7, \mathrm{~F} 8)$ regions and from frontal $(\mathrm{Fz})$, central $(\mathrm{Cz})$, and parietal $(\mathrm{Pz})$ midline locations. In addition, several nonstandard sites were used, including Wernicke's area and its righthemisphere homologue (WL, WR: 30\% of the interaural distance lateral to a point $13 \%$ of the nasion-inion distance posterior to $\mathrm{Cz}$ ), posterior temporal (TL, TR: $33 \%$ of the interaural distance lateral to $\mathrm{Cz}$ ), and anterior temporal (ATL, ATR: one-half the distance between F7/F8 and T3/T4). Vertical eye movements and blinks were monitored by means of two electrodes, one placed beneath the left eye and one placed to the right of the right eye. The above 15 channels were referenced to an electrode placed over the left mastoid bone and were amplified with a bandpass of 0.01 to $100 \mathrm{~Hz}$ (3db cutoff) by a Grass Model 12 amplifier system. Activity over the right mastoid was actively recorded on a sixteenth channel to determine if there were any effects of the experimental variables on the mastoid recordings. No such effects were observed.

Continuous analog-to-digital conversion of the EEG and stimulus trigger codes was performed by a Data Translation 2801-A board and a 486-based computer at a sampling frequency of $200 \mathrm{~Hz}$. Epochs were comprised of the $100 \mathrm{msec}$ preceding and the $1180 \mathrm{msec}$ following presentation of individual words in the sentences. Trials characterised by excessive eye movement or amplifier blocking were removed prior to averaging. ERPs were quantified as the mean voltage within a latency range following presentation of words of interest relative to a baseline of activity comprised of the $100 \mathrm{msec}$ prior to presentation of the words of interest. Analyses of variance were performed on mean amplitude within four time windows: 50-150, 150-300, 300-500, and 500-800 msec. These windows were chosen because they roughly correspond to the latency ranges of the N1, P2, N400, and P3/P600 components often reported in cognitive ERP studies. Data acquired at midline and lateral sites were treated separately to allow for quantitative analysis of hemispheric differences. Two-way ANOVAs with repeated measures on sentence type and electrode site were performed on data from midline sites. Three-way ANOVAs with repeated measures on sentence type, hemisphere, and electrode site were performed on data from lateral sites. To protect against Type I error due to violations of the assumption of equal variances of differences between conditions of within-subject factors, the GreenhouseGeisser (1959) correction was applied when evaluating effects with more than one degree of freedom. The corrected $P$ value is reported for analyses involving the Greenhouse-Geisser correction. Reliable main effects and 
interactions were followed, when appropriate, by simple effects analyses; the error term for these analyses was the within-group mean square error from the original analysis of variance (cf. Keppel, 1982). ${ }^{3}$

\section{Results and Discussion}

\section{Acceptability judgements}

Subjects judged the nonanomalous control, semantically anomalous, and syntactically anomalous sentences to be acceptable on $87 \%, 12 \%$, and $1 \%$ of the trials, respectively.

\section{ERPS}

Critical words. Grand-average ERPs elicited by the critical words in the three sentence types are shown in Fig. 1. (Ten per cent of the trials were rejected for artefact, roughly evenly distributed across conditions.) In this and all subsequent figures, the general shapes of the waveforms were consistent with previously reported data (Neville, Kutas, Chesney, \& Schmidt, 1985; Osterhout \& Holcomb, 1992). A clear negative-positive complex was visible in the first $300 \mathrm{msec}$ following word onset (the "N1P2" complex). These potentials were followed by a negative-going component with a peak around $400 \mathrm{msec}$ (N400).

Inspection of Figure 1 reveals clear differences across conditions. Between roughly 300 and $500 \mathrm{~ms}$, semantic anomalies elicited a widely distributed increase in the N400 component, an effect that was largest over centroposterior sites. Within the same time window, ERPs to syntactic anomalies were more negative-going than controls over lateral sites, maximal over left anterior sites, and more positive-going than controls over posterior midline sites. The syntactic anomalies also elicited a largeamplitude, posterior-maximal positive shift with an onset around $500 \mathrm{msec}$ and a duration of several hundred msec. This positive shift was highly similar to the P600 effect previously reported in the response to a variety of syntactic anomalies (cf. Osterhout, 1994).

The results of statistical analyses confirmed these observations. No reliable differences were observed between 50 and $300 \mathrm{msec}$. ANOVAs on

\footnotetext{
${ }^{3}$ We performed no items analyses on these data. This reflects limitations imposed by the signal-averaging procedure used to derive ERPs. Items analyses in the present studies would involve forming grand averages over only 15 (Experiment 1) or 16 (Experiment 2) subjects, a number insufficient to obtain the desired signal-to-noise ratio. For discussion of this issue, see Osterhout (1994). Also, all artefact-free trials were included in the grand averages and associated statistical analysis, regardless of subjects' behavioural judgements. This was done to maximise the signal-to-noise ratio in the averages. Response-contingent averages would have eliminated too many trials in many of the experimental conditions.
} 


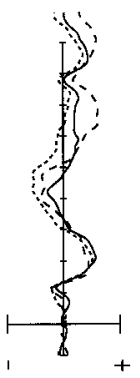

恵

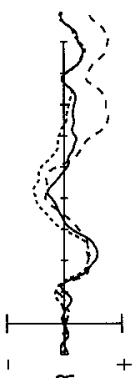

学

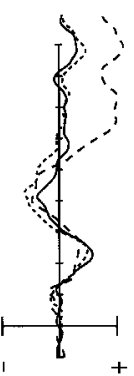

$\stackrel{x}{\Perp}$

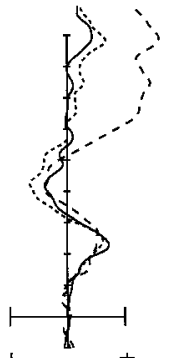

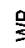

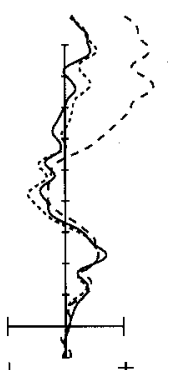

$\sigma^{+} \stackrel{g}{E}$

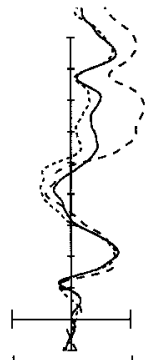

พ

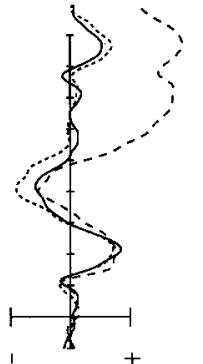

N
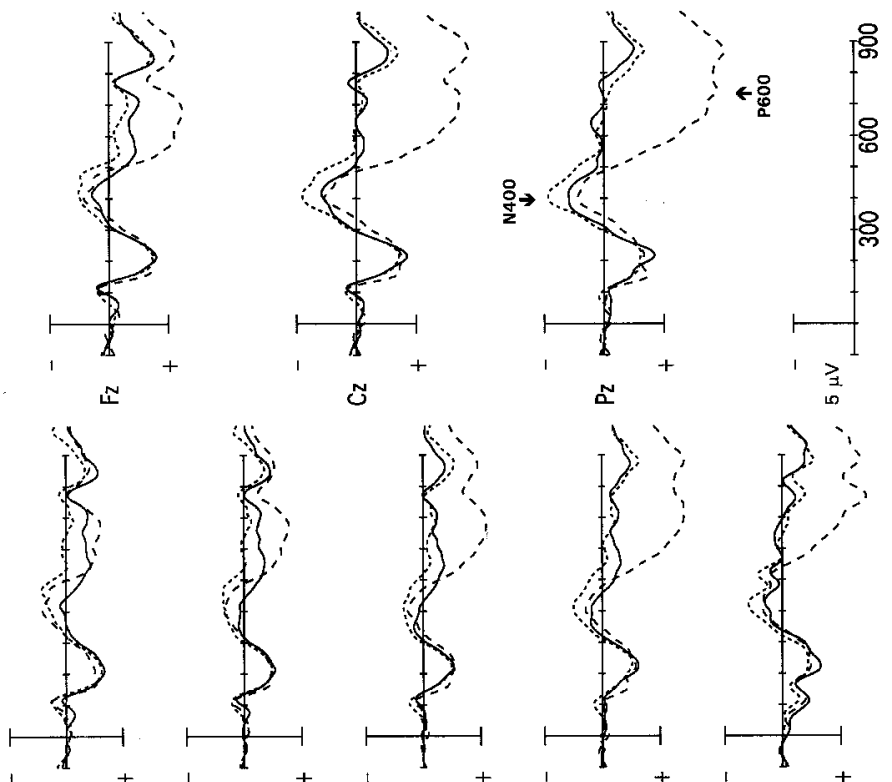

욘

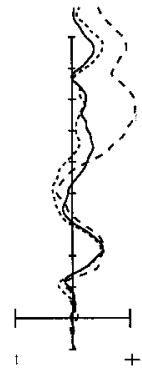

$\rightleftharpoons$

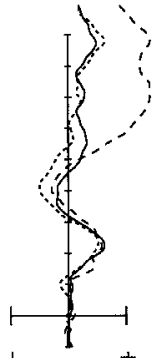

I

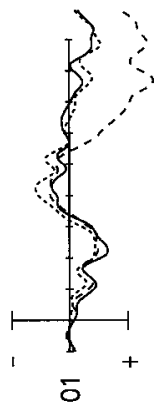

悘

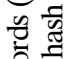

$3 \frac{1}{8}$

을

츨

츄ㅇㅝㅠ

悤

零

बิ

믁

足.

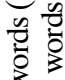

을

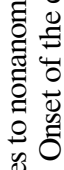

营

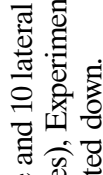

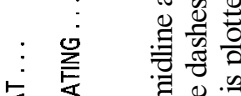

岳要 吕

7 on

"

范

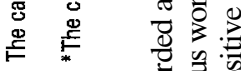

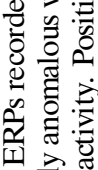

$\Phi_{0}$ त्रु

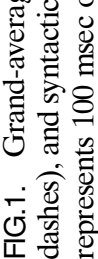


mean amplitude between 300 and 500 msec revealed a main effect for sentence type [midline, $F(2,28)=4.91, P=0.01$; lateral, $F(2,28)=4.70$, $P 5$ 0.02] and a marginally reliable interaction between sentence type and electrode position at midline sites, $[F(4,56)=2.97, P 5$ 0.08]. Simple effects analyses revealed that ERPs to semantic anomalies were reliably more negative-going than were those to controls [midline, $F(1,14)=10.91$, $P 50.01$; lateral, $F(1,14)=10.78, P 50.01$ ] and syntactic anomalies [midline, $F(1,14)=8.35, P 5 \quad 0.02$; lateral, $F(1,14)=6.28, P 5 \quad 0.03$ ]. At midline sites, ERPs to syntactic anomalies were reliably more positivegoing at posterior sites than those to controls [sentence type $\times$ electrode site: $F(2,28)=3.44, P=0.05]$ and semantic anomalies $[F(2,28)=3.51, P 5$ $0.05]$. However, the left-anterior negativity elicited by syntactic anomalies was not reliably different from ERPs elicited by the controls, $P 40.2$ in all analyses.

Within the 500-800 msec window, reliable differences between conditions were observed [midline, $F(2,28)=49.34, P 5 \quad 0.0001$; lateral, $F(2,28)$ $=24.16, P 5$ 0.0001], and these differences were largest posteriorly [sentence type $\times$ electrode site: midline, $F(4,56)=12.98, P 50.0001$; lateral, $F(8,112)=6.47, P 5$ 0.001] . Simple effects analyses indicated that ERPs to the syntactic anomalies were more positive-going than those to the other two conditions [nonanomalous controls: midline, $F(1,14)=70.51$, $P 5 \quad 0.0001$; lateral, $F(1,14)=30.08, P 50.001$; semantic anomalies: midline, $F(1,14)=77.67, P 5 \quad 0.0001$; lateral, $F(1,14)=33.51, P 5 \quad 0.001$ ], and that these differences were largest posteriorly [sentence type $\times$ electrode site; nonanomalous controls: midline, $F(2,28)=21.11, P 5$ 0.0001 ; lateral, $F(4,56)=8.02, P 5 \quad 0.001$; selectional restriction violations: midline, $F(2,28)=12.80, P 5 \quad 0.0001$; lateral, $F(4,56)=4.84, P 5 \quad 0.01$ ]. ERPs to semantically anomalous words did not reliably differ from those to nonanomalous controls in this window.

Sentence-final words. ERPs elicited by the sentence-final words in each sentence condition are shown in Fig. 2. At most electrode sites, ERPs to the final words in the two anomalous sentence types were more negativegoing than ERPs to the final words in nonanomalous sentences, beginning at about $200 \mathrm{msec}$ and continuing for the remainder of the epoch (ANOVA on mean amplitude between 300 and $500 \mathrm{msec}$, midline sites: $F(2,28)=17.32, P 50.001)$. Simple effect analyses revealed that ERPs to both types of anomalous words were more negative-going than ERPs to nonanomalous controls [sectional restriction: midline, $F(1,14)=21.76$, $P 50.001$ verb tense: midline, $F(1,14)=29.51, P 50.001]$. No reliable differences were found in the ERPs to the two types of anomalies, $F 51$.

Thus, consistent with previous reports, syntactic and semantic anomalies elicited qualitatively distinct changes in the ERP. Experiment 2 was 

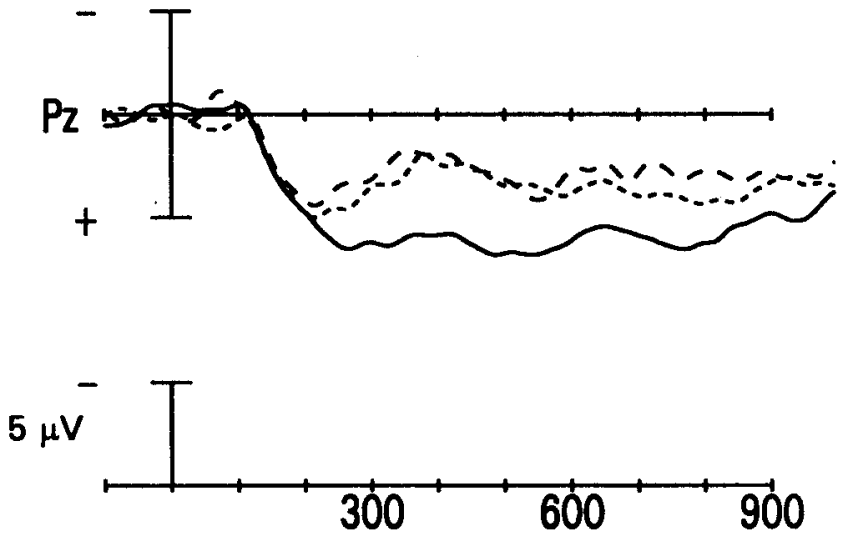

\section{- ... eat the food ... on the PORCH. \\ -.... ?... bake the food ... on the PORCH. \\ -.... *eating the food ... on the PORCH.}

FIG. 2. Grand-average ERPs (recorded at site Pz) to sentence-final words in nonanomalous sentences (solid line), sentences containing a semantic anomaly (small dashes), and sentences containing a syntactic anomaly (large dashes).

designed to replicate this finding and to investigate the independence of these brain responses.

\section{EXPERIMENT 2}

\section{Methods}

Subjects. Sixteen undergraduate and graduate students (11 females and 5 males), none of whom participated in Experiment 1, participated for course credit or for a small compensation. Subjects ranged in age from 18 to 31 years.

Materials. An additional 30 sentence frames were added to the 90 experimental sentence frames presented in Experiment 1. (Minor modifications were made to a few of the materials presented in Experiment 1 in order to increase the degree of semantic anomaly, as determined by experimenter judgements.) Four versions of each 
sentence frame were then constructed. The first three versions were identical to those presented in Experiment 1. The fourth version contained a verb that was both semantically (selectional restriction violation) and syntactically (tense violation) anomalous (see Table 1). These materials were used to create four stimulus lists, such that each subject saw one version of each sentence frame and 30 exemplars of each of the four sentence types. Ninety filler sentences were then added to each list. Thirty of these sentences contained a reflexive pronoun that agreed in number, gender, and case with its antecedent (e.g., "The children ingratiated themselves with the kindly uncle."); 30 contained a reflexive that mismatched in number with the antecedent noun (e.g., "The children ingratiated himself with the kindly uncle."); and 30 were simple active structures containing no anomalies. Thus, each subject saw 210 sentences. Ninety of these sentences were nonanomalous; 60 contained a syntactic anomaly (verb tense violation or reflexiveantecedent agreement violation); 30 contained a semantically anomalous word; and 30 contained a verb that was both syntactically and semantically anomalous.

Procedure. All procedures were identical to those used in Experiment 1.

\section{Results and Discussion}

\section{Acceptability judgements}

Subjects judged the nonanomalous control, semantically anomalous, syntactically anomalous, and doubly anomalous sentences to be acceptable on $83 \%, 9 \%, 1 \%$, and $1 \%$ of the trials, respectively.

\section{ERPS}

ERPs were analysed using a factorial design involving the within-subject factors of grammaticality (grammatical vs ungrammatical) and semantic plausibility (plausible vs implausible), in addition to the within-subject factors of electrode site and hemisphere. The main effects of grammaticality and semantic plausibility allowed us to evaluate the effects of each variable independently of the effects of the other variable. The presence of significant main effects in the absence of reliable interactions would be consistent with the claim that these brain responses are independent. Inspection of the waveforms revealed that small-amplitude differences in 
ERPs across conditions existed concurrent with word onset. Such differences are not plausibly due to the effects of the manipulated variables. In order to reduce the magnitude of these preexisting differences, we employed a 200-msec baseline comprised of the $100 \mathrm{msec}$ of activity preceding and the $100 \mathrm{msec}$ of activity following the onset of the critical words. 4

Critical words. Fourteen per cent of the trials were rejected for artefact, evenly distributed across treatment conditions. Figure 3 plots ERPs to semantically plausible and implausible verbs, collapsing over the grammaticality factor. Figure 4 plots ERPs to grammatical and ungrammatical verbs, collapsing over the semantic plausibility factor. Inspection of these figures shows quite clearly that, as in Experiment 1, ERPs elicited by syntactic and semantic anomalies were qualitatively distinct. Semantic anomalies elicited an increased negativity that was most robust between approximately 300 and $500 \mathrm{msec}$. This negativity persisted throughout the recording epoch at most electrode sites. Syntactic anomalies elicited a large-amplitude positive shift beginning at about $500 \mathrm{msec}$ and persisting throughout the epoch. This positivity was preceded by a slight increase in negativity (relative to the nonanomalous controls) over right-hemisphere sites, from about 400 to $500 \mathrm{msec}$.

Statistical analyses confirmed these observations. Within the 150-300 msec window, ERPs to semantically implausible verbs were more negative-going than those to semantically plausible verbs over lateral sites, reflecting the onset of the N400 effect $[F(1,15)=6.12, P 5 \quad 0.03]$. This effect increased in magnitude and was evident at all sites between 300 and $500 \mathrm{msec}$ [midline, $F(1,15)=7.37, P 5 \quad 0.02$; lateral, $F(1,15)=7.94, P 5$ 0.02]. ERPs to semantically implausible verbs continued to be more negative-going within the $500-800 \mathrm{msec}$ window, particularly at lateral sites (lateral, $F(1,15)=7.08, P 5 \quad 0.02$; midline, $F(1,15)=3.44, P 50.1$ ] ERPs to grammatical and ungrammatical verbs did not differ between 150 and $300 \mathrm{msec}$. Although syntactic anomalies elicited an increased negativity over right-hemisphere sites, this effect was not statistically robust within the $300-500 \mathrm{msec}$ window [grammaticality $\times$ hemisphere: $F(1,15)=3.24, P=0.09]$. However, an analysis on mean amplitude between 400 and $500 \mathrm{msec}$, encompassing the temporal extent of the effect, did find a reliable interaction $[F(1,15)=7.72, P 5 \quad 0.02]$. The large positive shift elicited by the syntactically anomalous words was highly reliable, as confirmed by a main effect of grammaticality within the $500-800 \mathrm{msec}$

\footnotetext{
${ }^{4}$ Results of statistical analyses using the standard $100-\mathrm{msec}$ prestimulus baseline were highly similar to those reported.
} 


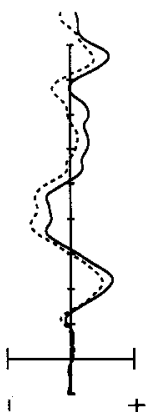

乎

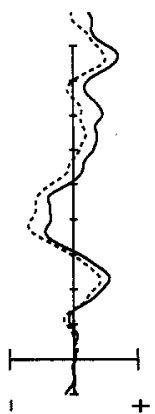

孚

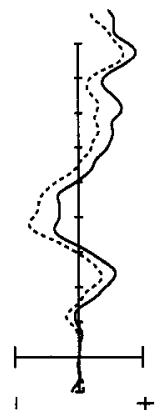

똗

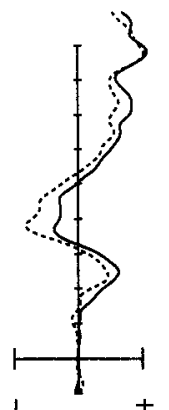

孚

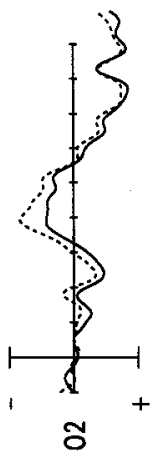

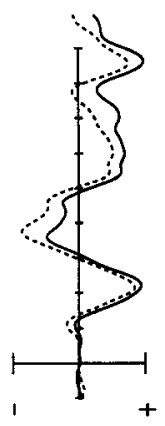

พ
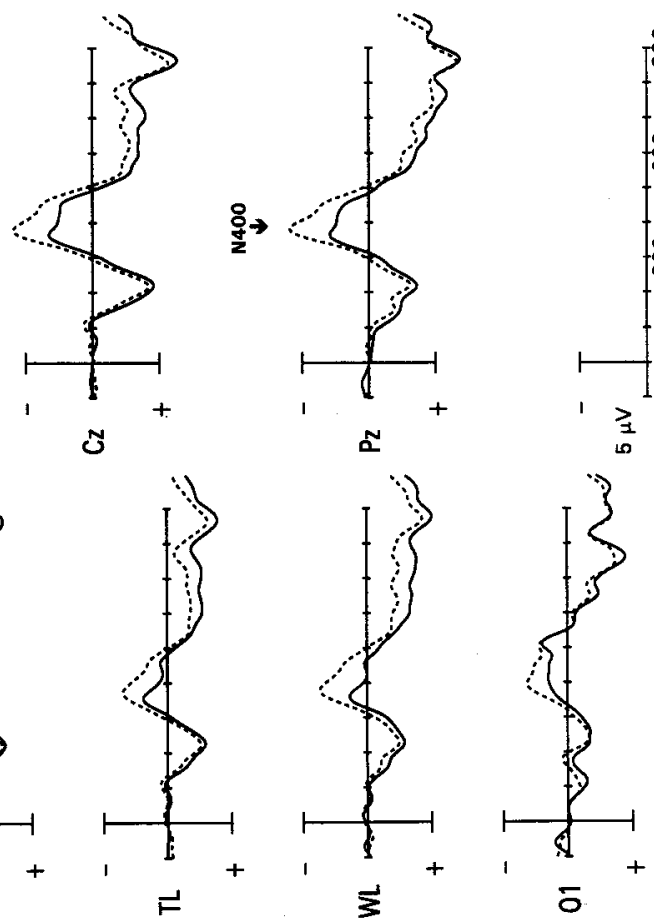

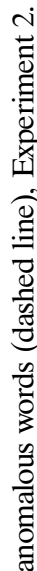

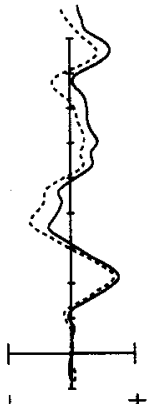

II

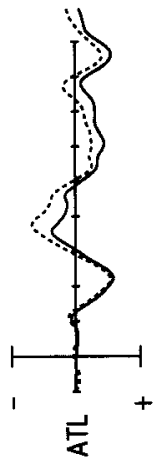

F

$\xi$

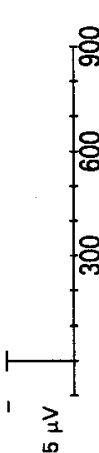

흠

8

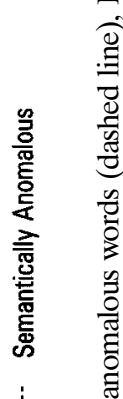

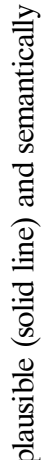

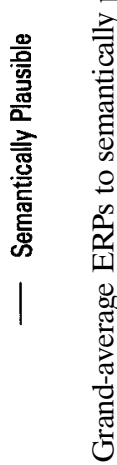

लं

욛 

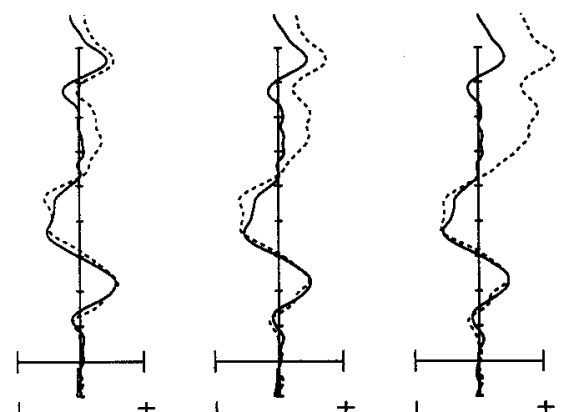

$\infty$

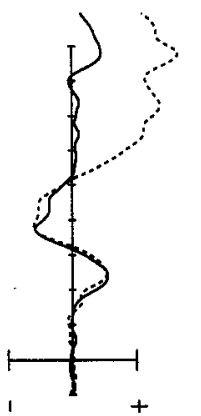

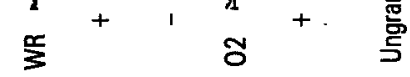
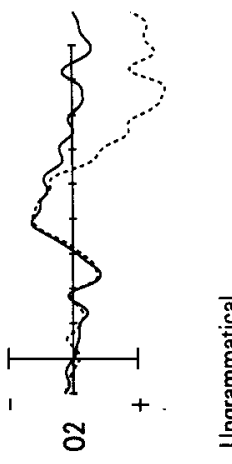
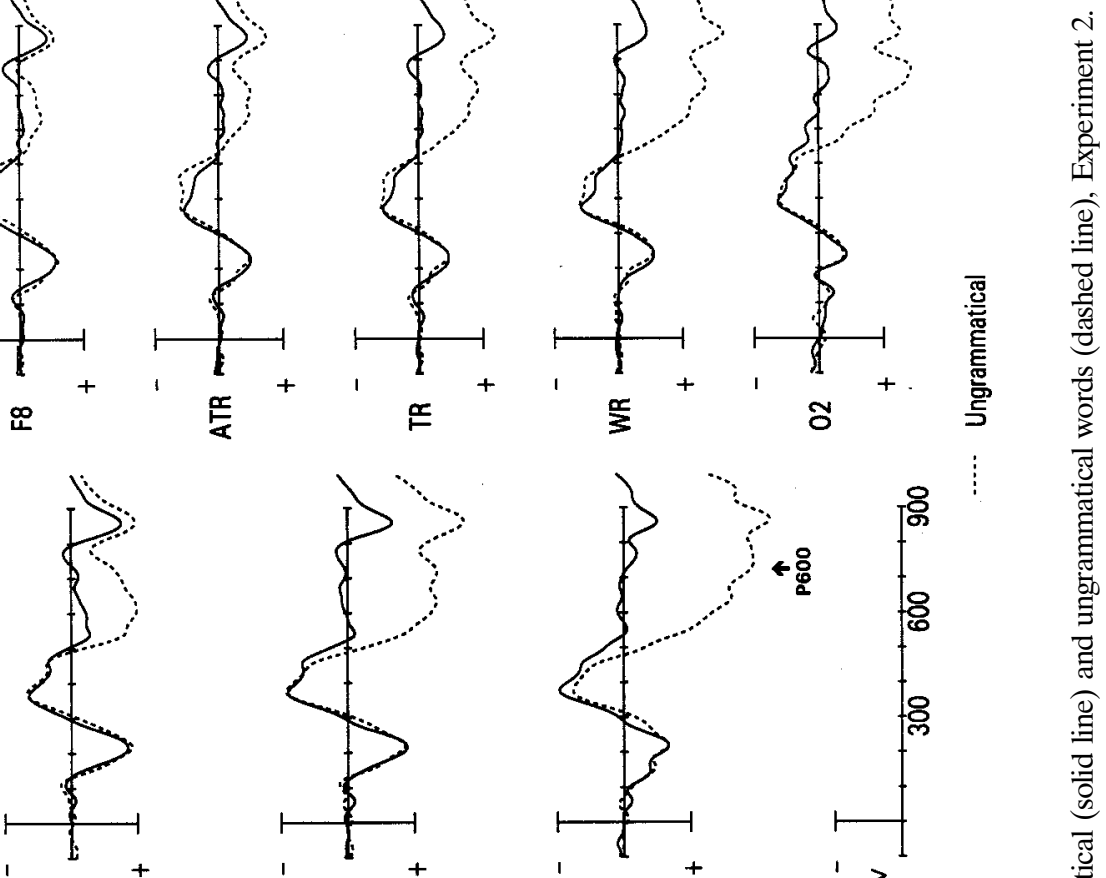

ำ
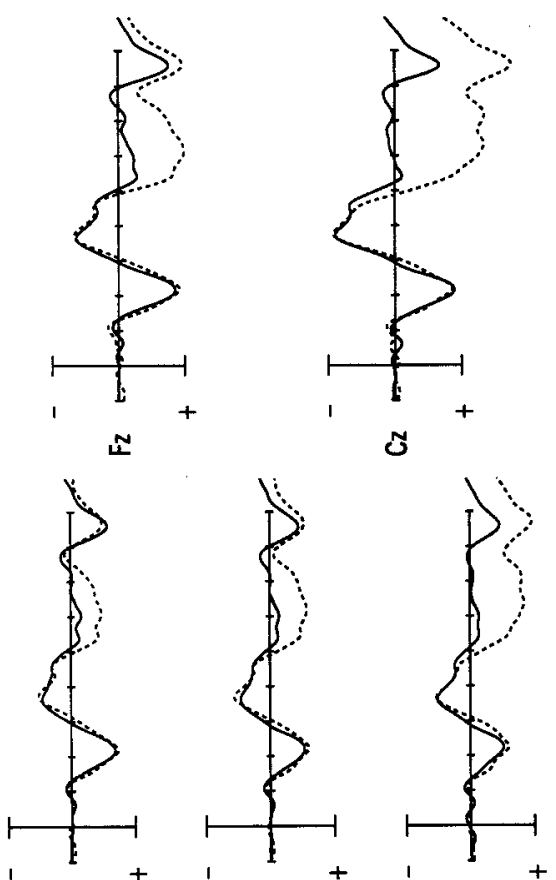

I

F

$\vec{F}$

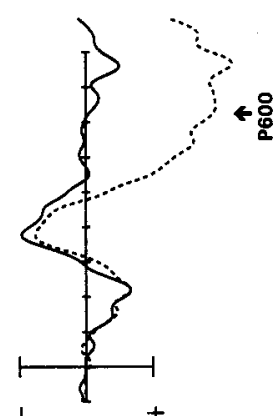

용

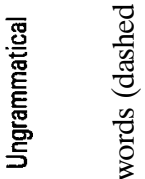

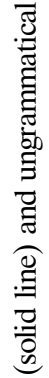

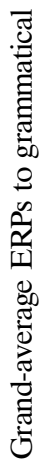

ர் 
window [midline, $F(1,15)=28.35, P 5 \quad 0.001$; lateral, $F(1,15)=21.92, P 5$ 0.001 . This effect was largest posteriorly [grammaticality $\times$ electrode site: midline, $F(2,30)=13.18, P 5 \quad 0.001$; lateral $F(4,60)=8.95, P 5 \quad 0.001]$.

Evidence of nonlinearity would take the form of reliable interactions between the grammaticality and semantic plausibility factors. However, none of these interactions was statistically robust. Two interactions were marginally reliable: the three-way interaction between grammaticality, plausibility, and hemisphere between 300 and $500 \mathrm{msec}[F(1,15)=3.69$, $P=0.07]$, and the two-way interaction between grammaticality and plausibility at midline sites between 500 and $800 \mathrm{msec}[F(1,15)=3.68$, $P=0.07]$.

The observed pattern of robust main effects, together with weak or nonexistent interactions, suggests a considerable degree of independence in the response to the two types of anomaly. If this is correct, then one would expect the doubly anomalous words to elicit both an N400 effect and a P600 effect within the same epoch, relative to the nonanomalous controls. Furthermore, the amplitudes of these effects should be similar to those elicited by each type of anomaly independently. Exactly this result was observed (Fig. 5).

In order to directly visualise the main effects and interactions, three sets of difference waves were derived. Difference waves isolate the effects of interest and provide the clearest representation of the scalp distribution, morphology, and temporal course of these effects. Main effects were isolated by subtracting ERPs to the semantically coherent critical words from ERPs to the semantically anomalous words (Fig. 6) and by subtracting ERPs to the grammatical words from ERPs to the ungrammatical words (Fig. 7). Difference waves representing interactions were derived through a more complicated procedure. Under the assumption of simple additivity, ERPs to the doubly anomalous words, $\left(v t_{V}, s r_{V}\right)$, should be equivalent to a composite waveform algebraically constructed from three components: the response to the nonviolating control words, $\left(v t_{N V}, s r_{N V}\right)$, plus the effects of the verb tense violations alone, $\left(v t_{V}, s r_{N V}\right)$, plus the effects of the selectional restriction violations alone, $\left(v t_{N V}, s r_{V}\right)$, That is:

$$
\begin{aligned}
\left(v t_{V}, s r_{V}\right),= & \left(v t_{N V}, s r_{N V}\right)+\left[\left(v t_{V}, s r_{N V}\right)-\left(v t_{N V}, s r_{N V}\right)\right] \\
& +\left[\left(v t_{N V}, s r_{V}\right)-\left(v t_{N V}, s r_{N V}\right)\right]
\end{aligned}
$$

If the effects of syntactic and semantic anomaly summate perfectly, then there should be no significant deviations between the composite waveform and the observed waveform elicited by the doubly anomalous words; i.e., the difference wave formed by subtracting the observed waveform from the composite waveform should approximate a flat line with a voltage of zero. Deviations from zero represent deviations from the linear model (i.e., 

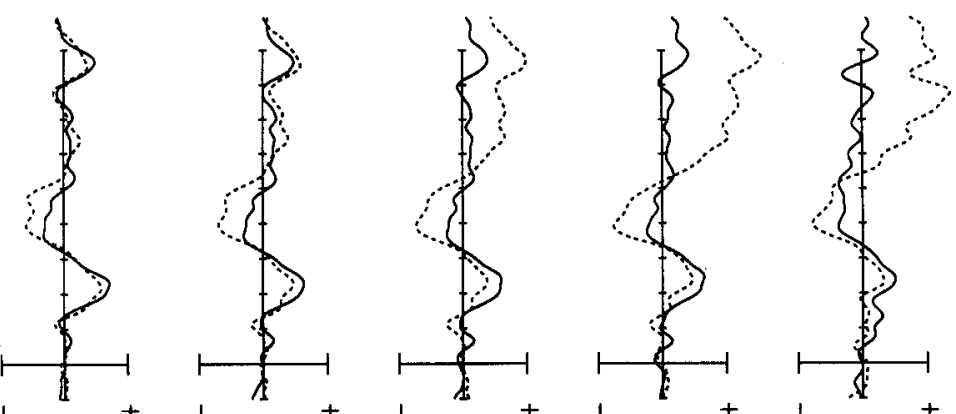

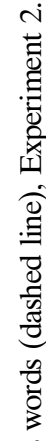

$\stackrel{\infty}{\mathbb{1}}$

敛

$\cong$
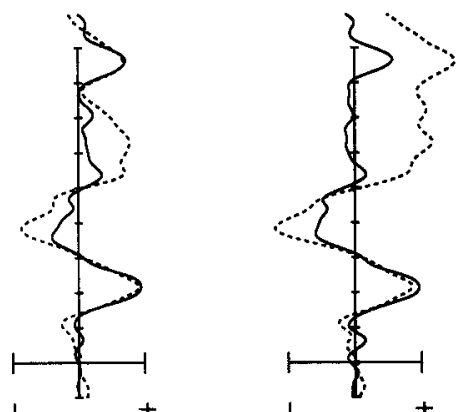

N
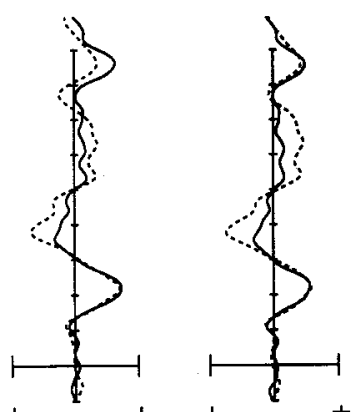

o

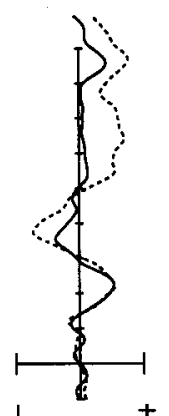

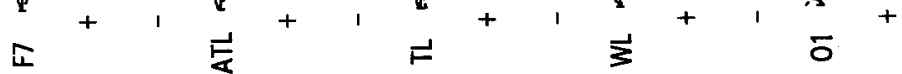
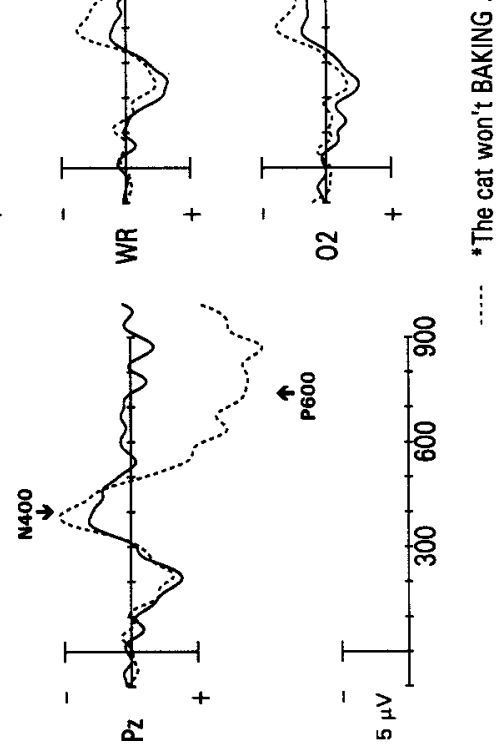

$\frac{0}{\tilde{c}}$

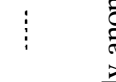




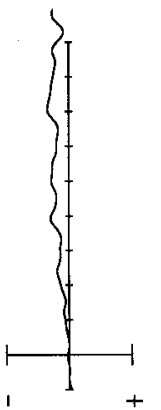

ㅁ⿺ㄴ

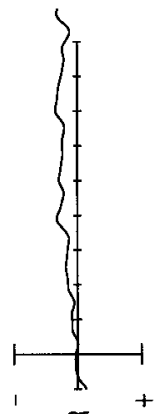

妥

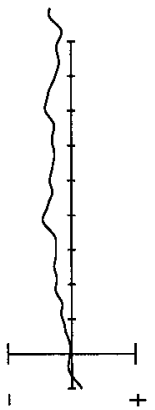

r

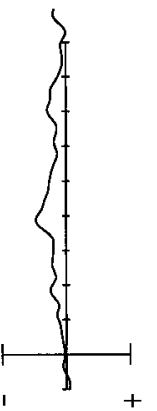

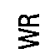

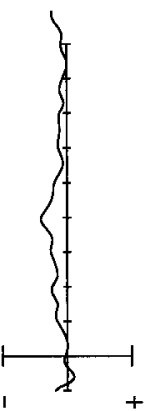

ถึํำ

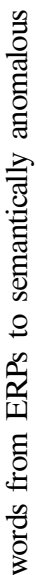
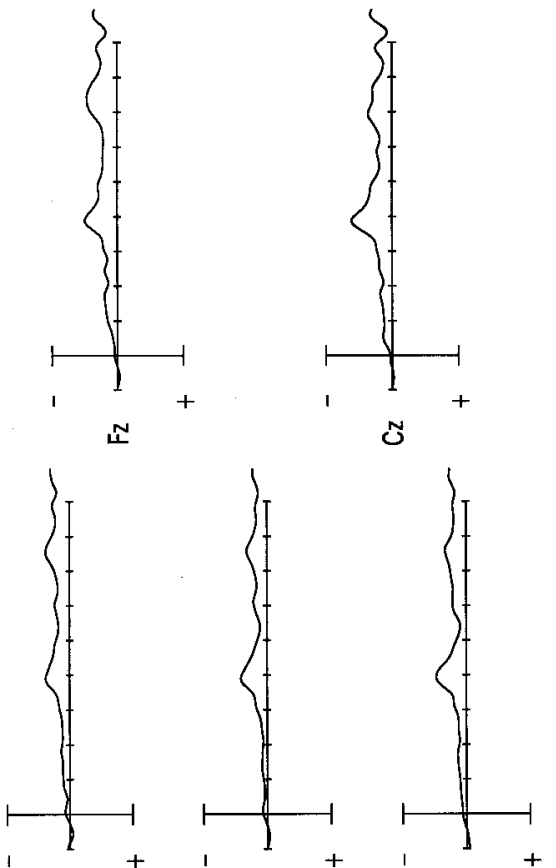

安

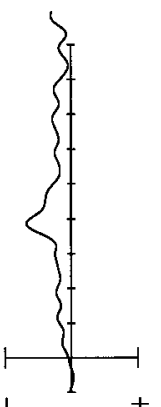

N

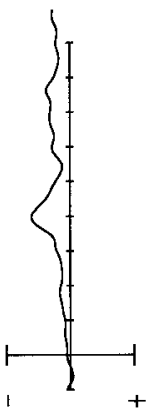

$\$$
各

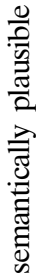

호

:

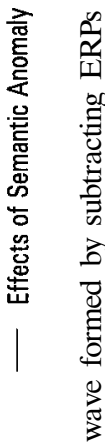

ช্

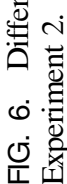




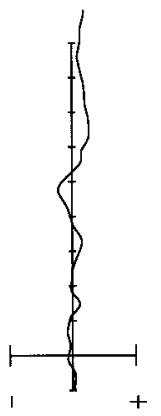

$\infty$

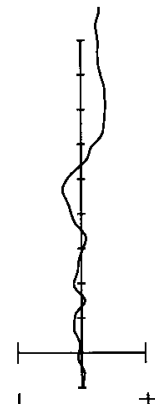

学

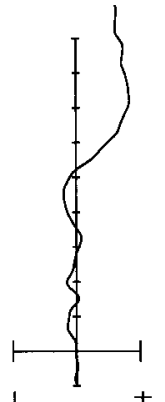

$\stackrel{+}{*}$

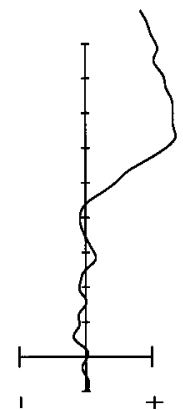

o

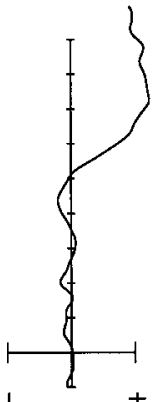

孚 +
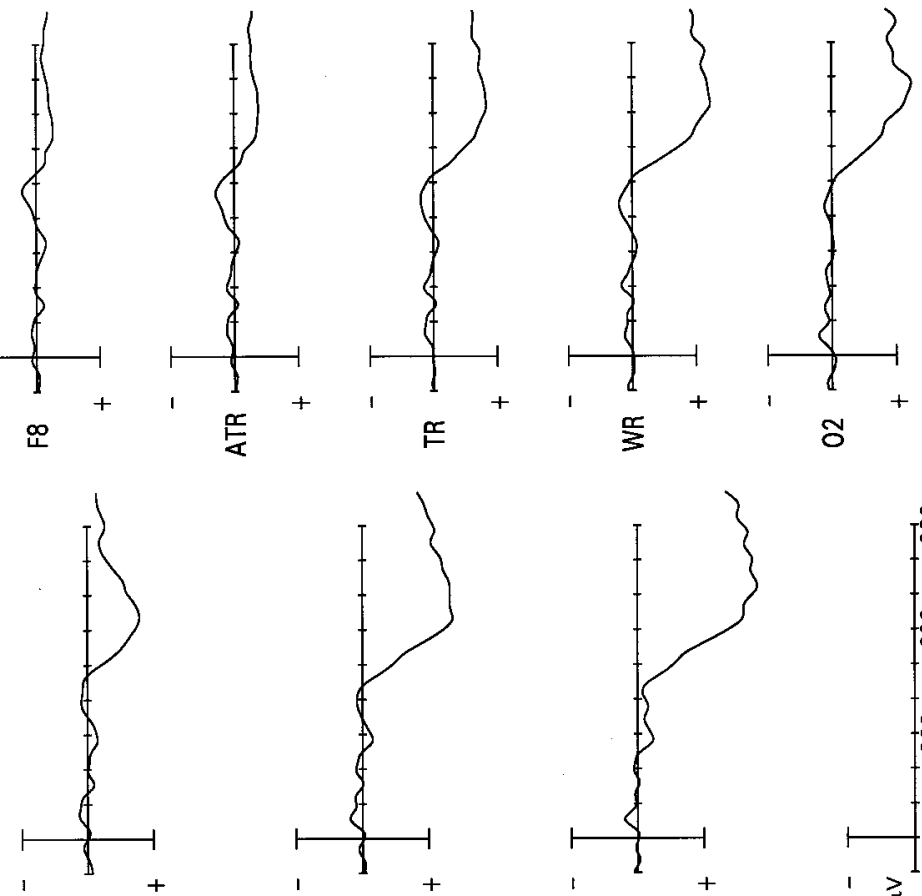

는
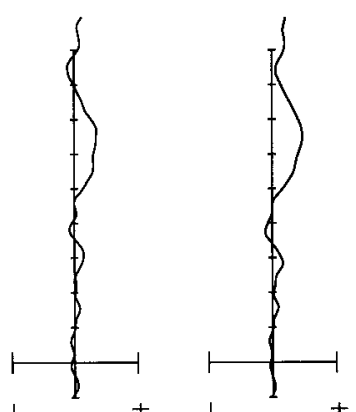

II

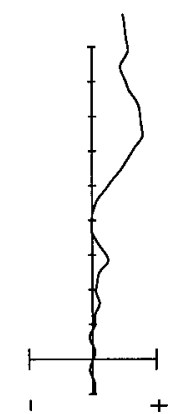

F

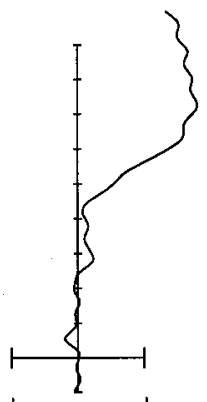

N

苐
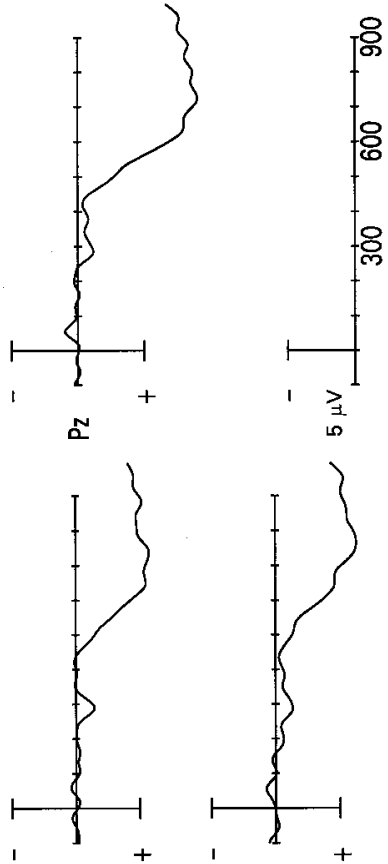

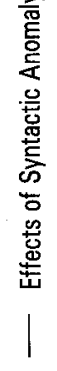

욤

泀

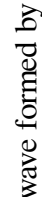

遇

N

迹 
interactions). Specifically, negative and positive deflections indicate that the linear model predicted more negativity and positivity, respectively, than was observed in the response to doubly anomalous words. Figure 8 shows that some deviations from zero did occur. Between roughly 200 and $500 \mathrm{msec}$, ERPs were less negative than was predicted by the linear model, particularly over right-hemisphere sites. Beginning at about $500 \mathrm{msec}$ and continuing throughout the epoch, ERPs were less positive than predicted by the linear model, particularly over midline and posterior sites. These deviations from linearity were reflected in the marginally reliable interactions reported above.

In order to obtain a finer-grained analysis of the time course of the main effects and interactions plotted in Figs. 6-8, ANOVAs were performed on mean amplitude within successive 100-msec windows (beginning at $200 \mathrm{msec}$ poststimulus). For the semantic condition (Fig. 6), reliable differences were found between 300 and 400 [midline, $F(1,15)=9.02, P 5$ 0.01 ; lateral, $F(1,15)=8.94, P 5 \quad 0.01$ ], 400 and 500 [midline, $F(1,15)=$ 5.00, $P 5$ 0.05; lateral, $F(1,15)=6.44, P 50.03$ ], 600 and 700 [lateral, $F(1,15)=5.53, P 5$ 0.04], and 700 and $800 \mathrm{msec}$ [midline, $F(1,15)=4.18, P$ $=0.05$; lateral, $F(1,15)=8.79, P 50.01]$. Thus, the negative-going activity elicited by semantic anomalies was most robust within the N400 window but persisted throughout much of the recording epoch. For the syntactic condition (Fig. 7), ERPs to syntactic anomalies were reliably negative over right-hemisphere sites between 400 and $500 \mathrm{msec}$, as noted above. Reliable differences were also found between 500 and 600 [midline, $F(1,15)=17.24$, $P 5$ 0.001; lateral, $F(1,15)=23.04, P 50.001$ ], 600 and 700 [midline, $F(1,15)=31.46, P 5 \quad 0.0001$; lateral, $F(1,15)=23.04, P 5 \quad 0.001]$, and 700 and $800 \mathrm{msec}$ [midline, $F(1,15)=26.09, P 5 \quad 0.001$; lateral, $F(1,15)=32.83$, $P 5$ 0.0001]. The critical analyses involved the deviations from linearity shown in Fig. 8. Reliable or marginally reliable nonlinearities were found between 300 and $400 \mathrm{msec}$, but only in the right hemisphere $[F(1,15)=$ $6.49, P 50.03]$ and at midline sites between 600 and $700 \mathrm{msec}[F(1,15)=$ $3.89, P=0.06]$. For all other analyses, $P 50.15$.

Thus, under the current experimental conditions, the response to words that were both syntactically and semantically anomalous approximated the linear summation of the response to each type of anomaly in isolation from the other type. However, the summation was not perfectly linear. Reliable interactions were found between 300 and $400 \mathrm{msec}$ and between 600 and $700 \mathrm{msec}$. Although the sources of these nonlinearities cannot be determined definitively given present data, one hypothesis notes that salient stimulus events occurred within these two time windows. Specifically, relative to critical word onset, the offset of the critical word occurred at $350 \mathrm{msec}$ and the onset of the subsequent word occurred at $650 \mathrm{msec}$. One speculation is that the nonlinearities were introduced by 

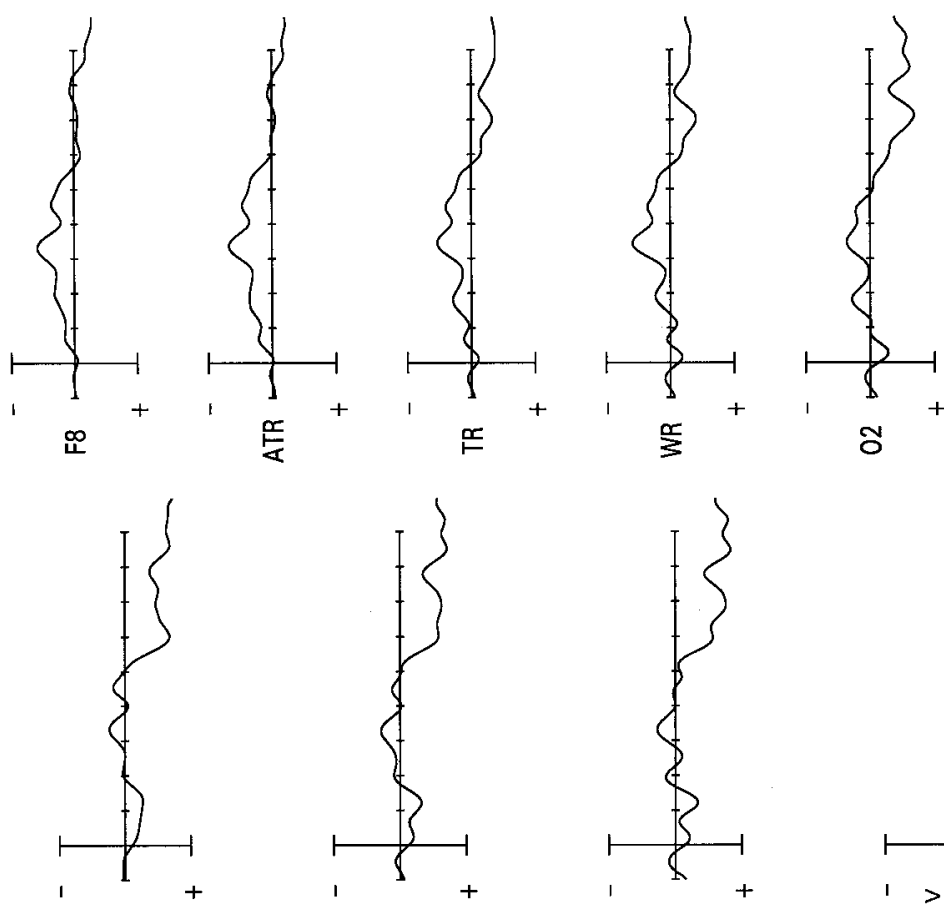

N
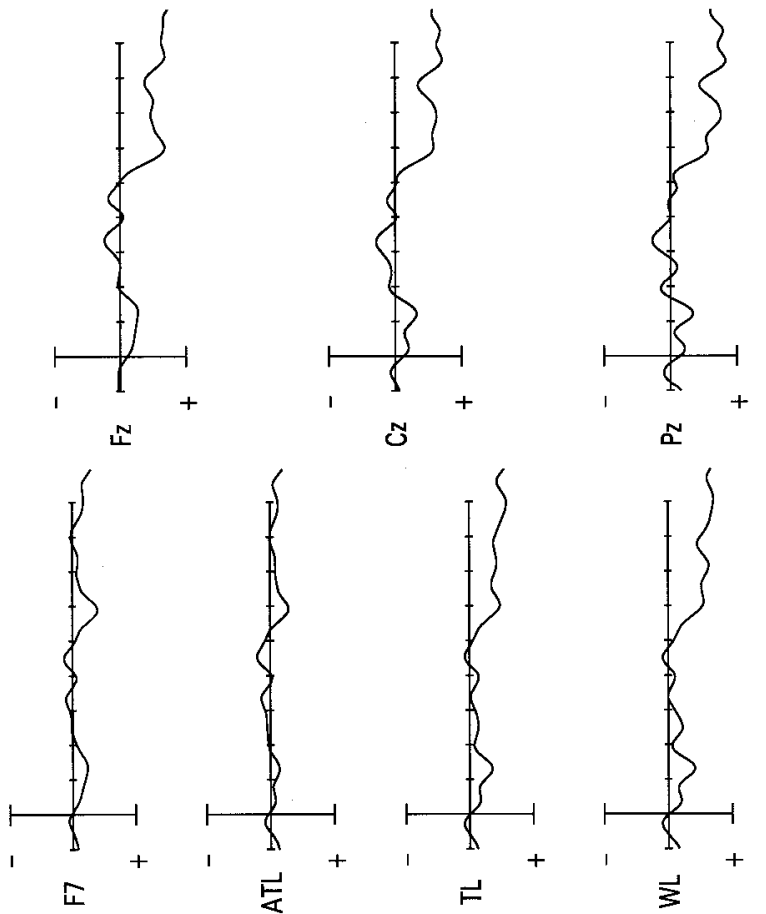

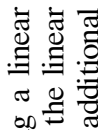

苯

कै

ट्ञ

틀 믐

융 응

过

.

․ㅡㄹ

을 줄

ช 들 흠

응 웅

告

잉

용

合方

올 옴

18

힝

층

궁 응

을.

흐응

모월

引

ह क जै

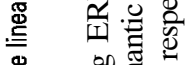

幽 क

흔 矛它

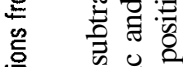

.옳 क

总 ह

运交

응

ڤ 巳

त क्षे

$8 \stackrel{0}{0}$

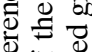

可

คิ สี่

$\infty$ 䰹

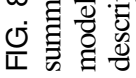


these stimulus events, as there is no reason to expect the ERP responses to these events to summate in the doubly anomalous condition.

Sentence-final words. ERPs recorded over site Pz to the sentence-final words are shown in Fig. 9. As in Experiment 1, ERPs to the final word in sentences containing an anomalous word elicited ERPs that were more negative-going than those to final words in nonanomalous sentences. Furthermore, at $\mathrm{Pz}$ the negative-going activity elicited by sentence-final words in doubly anomalous sentences (relative to the nonanomalous sentences) was approximately an additive function of the negative-going activity elicited by the final words in the syntactically and semantically anomalous sentences. This additivity was less evident at other sites. Correspondingly, an ANOVA on mean amplitude between 300 and $500 \mathrm{msec}$ recorded over midline sites revealed reliable main effects of
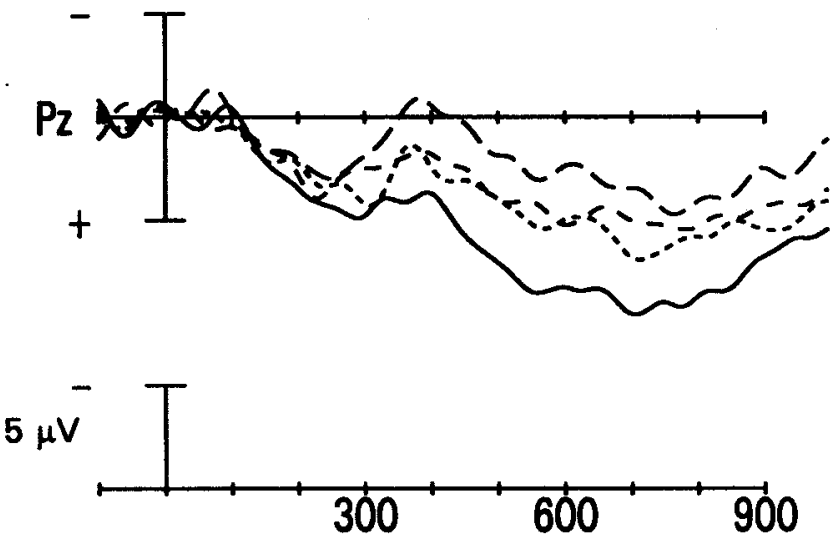

- ...eat the food ... on the PORCH.

.... ? ... bake the food ... on the PORCH.

.... * eating the food ... on the PORCH.

- ${ }^{*}$... baking the food ... on the PORCH.

FIG. 9. Grand average ERPs (recorded at site Pz) to sentence-final words in nonanomalous sentences (solid line), sentences containing a selectional restriction violation (small dashes), sentences containing a verb tense violation (large dashes), and sentences containing a doubly anomalous word (broken line), Experiment 2. 
grammaticality $[F(1,15)=6.06, P 50.03]$ and semantic plausibility $[F(1,15)=10.23, P 50.01]$. A three-way interaction between grammaticality, semantic plausibility, and electrode site reflected the fact that the additivity was much more evident at $\mathrm{Pz}$ than at $\mathrm{Fz}$ and $\mathrm{Cz}[F(2,30)=4.60$, $P 550.05]$.

\section{GENERAL DISCUSSION}

Under conditions in which the word class of the critical word, preceding and following context, and task were identical across anomaly type, syntactic and semantic anomalies elicited qualitatively distinct changes in the ERP waveform. Semantically anomalous selectional restriction violations elicited an increase in the amplitude of the N400 component (the N400 effect). Syntactically anomalous verb tense violations elicited a large-amplitude positive shift (the P600 effect). Doubly anomalous words elicited both effects and the response to these anomalies approximated the linear summation of the two responses elicited independently. These results demonstrate that, at least under the conditions of the current experiment, the N400 and P600 effects elicited by semantic and syntactic anomaly, respectively, are both qualitatively distinct and largely independent.

How do these findings relate to the central question of the distinctiveness and independence of syntactic and semantic processing? The permissible inference is that at least a subset of the neural (and by extension cognitive) processes that respond to these categories of anomaly are separable and largely independent. Such a finding is consistent with the claim that separable and independent syntactic and semantic processes exist (cf. Osterhout \& Hagoort, 1999). However, we know very little about the cognitive processes made manifest by these language-sensitive ERP effects. In particular, we do not know whether these effects reflect linguistic processes directly or, instead, reflect processes that are correlated with but indeterminately removed from the linguistic processes themselves (Osterhout et al., 1997; Rugg \& Coles, 1995). Nor do we know for certain how the processes that respond to a linguistic anomaly relate to processes that occur in the absence of any anomaly. N400 amplitude is a function of the semantic congruence between the critical word and preceding context, even when the critical word is semantically appropriate. Correspondingly, researchers have suggested various functional accounts that relate N400 amplitude to a process that putatively occurs during "normal" processing (e.g., spread of activation through a semantic network, or semantic integration of the critical word with preceding contextual material; Brown \& Hagoort, 1993; Kutas, Lindamood \& Hillyard, 1984; Holcomb, 1993; 
Osterhout \& Holcomb, 1992). In such models the large-amplitude response to a semantically anomalous word represents one extreme of a semantic processing continuum. Very little evidence exists to support the parallel notion that P600 amplitude reflects one extreme of a syntactic processing continuum (but see Osterhout et al., 1994, for evidence that could be construed this way).

These limitations in our knowledge of underlying processes are particularly important when considering how the present findings relate to previous claims about the modularity or "informational encapsulation" of syntactic processing (Fodor, 1983; Forster, 1979). Although some findings have been taken as evidence that the initial syntactic analysis of a sentence is unaffected by semantic and pragmatic knowledge (Ferreira \& Clifton, 1986; Fodor, 1983; Frazier, 1987; Rayner, Carlson \& Frazier, 1983), other findings suggest that semantic and pragmatic information can be used very quickly to influence the earliest stages of syntactic analysis (Altmann, 1998; Marslen-Wilson \& Tyler, 1987; Ni et al., 1996). The present findings demonstrate that the brain responds quite differently to syntactic and semantic/pragmatic anomalies, and that the response to each category of anomaly is relatively unaffected by the simultaneous presence of the other category of anomaly. However, until we know more about the underlying processes, stronger inferences about the separability and independence of linguistic processes remain premature.

These results allow a more definitive conclusion concerning the claim that syntactic and semantic anomalies elicit qualitatively distinct ERP responses (Hagoort et al., 1993; Osterhout \& Holcomb, 1992; Osterhout et al., 1997). In addition to the verb tense violations presented here, a disparate set of syntactic anomalies has been reported to elicit a late positive shift. This set includes anomalies involving phrase structure (Hagoort et al., 1993; Neville et al., 1991; Osterhout \& Holcomb, 1992), verb subcategorisation (Osterhout \& Holcomb, 1992; Osterhout et al., 1994), constituent movement (McKinnon \& Osterhout, 1996; Neville et al., 1991), agreement (Hagoort et al., 1993; Osterhout, 1997; Osterhout, Bersick, \& McLaughlin, 1997; Osterhout \& Mobley, 1995; Osterhout et al., 1996), and case (Coulson et al., 1998). One of the few properties shared by these disparate phenomena is that, in contrast to selectional restriction violations and other types of semantic and pragmatic anomalies, these words are syntactically illicit.

However, it is clear that this finding will not generalise to all experimental conditions. In some reports the response to syntactic anomalies has been dominated by a negative-going wave within the temporal window associated with the N400 component (i.e., between about 200 and 500 msec; Friederici et al., 1993; Kutas \& Hillyard, 1983; Münte et 
al., 1993; Rösler et al., 1993). Typically, this negativity has been widely distributed but largest over anterior (and sometimes left-anterior) regions. Other studies have reported a biphasic mixture of negative- and positivegoing effects in which a negativity precedes onset of the positive shift (Gunter et al., 1997, Exp. 1; Neville et al., 1991; Osterhout \& Holcomb, 1992; Osterhout \& Mobley, 1995). Similarly, in the present study syntactic anomalies elicited small-amplitude, lateralised negativities within the N400 window that preceded the P600 effect, although these negativities differed dramatically in the spatial properties across experiments and were not statistically robust. In a few studies semantic anomalies have also elicited a biphasic response in which an N400 effect was followed by a positive shift (Münte et al., 1998). The proper explanations for these cross-experiment differences remain unclear. There are a number of ways in which these experiments differ and these differences could affect the findings. Differences between experiments include the test point (sentenceembedded or sentence-final), the secondary task subjects are asked to do, and the language tested (for an extended discussion of these issues, see Osterhout, 1997). For example, Rösler et al. (1993) asked subjects to make lexical decisions to linguistically anomalous sentence-ending words. It is not entirely clear how the lexical decision task might interact with the response to a linguistic anomaly. ${ }^{5}$ Furthermore, given that different languages encode linguistic constraints differently, effects obtained in one language might not generalise to others. Most of the studies reporting negative-going effects to syntactic anomalies have presented sentences in German, whereas the majority of studies reporting a P600-like effect have presented sentences in English. Much of the grammatical work in English is encoded in constraints on word order, whereas in German much grammatical information is encoded in an extensive system of casemarking. At the least, caution is needed in comparing the responses to ostensibly similar linguistic constructions presented in different languages. In sum, regardless of the proper interpretation of the different results reported in the literature, the results reported here demonstrate once again

${ }^{5}$ In the current study, subjects were asked to perform a sentence-acceptability judgement after each sentence. Such a task renders the anomalies highly task relevant. This raises the possibility that the P600 effect might be a member of the P300 family of positivities elicited by a wide range of task-relevant, unexpected events (Donchin, 1981). However, P600-like positivities have been observed under conditions in which subjects passively read sentences without performing any additional task (Hagoort et al., 1993; Osterhout et al., 1996; Osterhout \& Mobley, 1995) and recent work indicates that the "P300" and "P600" have additive effects and respond differently to manipulations of probability, suggesting that these effects are neurally and functionally distinct. (For arguments for and against this claim, see Osterhout \& Hagoort, 1999, and Coulson et al., 1998.) 
that the N400 and P600 effects are consistently dissociable under the experimental conditions used here. ${ }^{6}$

Although the response to doubly anomalous words approximated a linear summation of the responses to each type of anomaly elicited independently, this function was not perfectly linear. Deviations from the linear prediction were observed throughout the recording epoch and reliable nonlinearities were found between 300 and 400 msec and between 600 and $700 \mathrm{msec}$ subsequent to critical word onset. The failure to find perfect additivity is not surprising, for several reasons. First, as noted in the introduction, ERPs reflect the summed postsynaptic activity in large groups of neurons; the sources of activity are not limited to the effects of interest. Second, perfect additivity requires that all of the neural sources that contribute to both effects summate perfectly. Third, the simplistic view of neocortical sources as consisting of a few localised generators that are picked up with maximum amplitude at the electrodes nearest to them is being replaced by a more complex dynamic view of neocortex in which distributed sources undergo nonlinear interactions at multiple levels (Nunez, 1981, 1990, 1998; Nunez et al., 1997). Thus, what is most striking about the present findings is the extent to which the data fit a simple linear model, given such complexities and the opportunities for nonlinear influences during the long temporal and large spatial extent of the effects of interest.

It is not possible at present to determine the sources of the deviations from the linear model that were observed here. Our hypothesis is that the more robust deviations were introduced by salient stimulus events, namely, the offset of the critical word at $300 \mathrm{msec}$ and the onset of the subsequent word at $650 \mathrm{msec}$. Another possibility is that the use of different words in

${ }^{6}$ A reviewer suggested that the different kinds of responses elicited by "syntactic" anomalies might be related to the extent to which a syntactic anomaly also involves meaning. This notion is consistent with the finding reported by Osterhout (1997). That study demonstrated that whereas sentence-embedded syntactically anomalous closed-class words elicit a monophasic P600 effect in all subjects with no increase in N400 amplitude, syntactically anomalous open-class words elicited a monophasic P600 effect in most subjects and a monophasic N400 effect in others. Open-class words contain much more semantic content than do closed-class words. Furthermore, inspection of the literature reveals that, in general, syntactically anomalous closed-class words elicit a monophasic P600 effect (sometimes preceded by a small-amplitude anterior negativity) whereas the response to syntactically anomalous open-class words is occasionally a mixture of N400- and P600-like effects, with predominantly P600-like effects. Osterhout (1997) demonstrated that this mixture is at least under some circumstances the result of individual differences, in which the majority of subjects exhibit a P600 effect to open-class syntactically anomalous words and a minority exhibit an N400 effect to such words; no individual subjects elicited a biphasic mixture of both effects. For a discussion of the implications of such results, see Osterhout (1997). 
the semantically coherent and anomalous conditions introduced some subtle nonlinearities. One should also keep in mind that ERPs are extracted from the ongoing electroencephalogram by means of a signalaveraging procedure that reduces but does not eliminate the "noise" from the "signal". In any case, some experimental conditions seem more likely than others to introduce influences that obscure an additive function. For example, placing the critical word at the end of the sentence (as was done in the Gunter et al., 1997, study) introduces a greater likelihood that the response to the anomaly will become confounded with activity related to sentence wrap-up, decision, and response variables, especially when subjects are asked to make a judgement and/or response at the end of each sentence. This possibility is made more likely given the evidence reported here and elsewhere of large-amplitude effects of sentence wellformedness on ERPs to sentence-final words, even when the final word itself is not anomalous (Osterhout, 1997; Osterhout \& Holcomb, 1992; Osterhout \& Mobley, 1995).

Upper-bound estimates of the time course of anomaly detection are provided by the onset of reliable divergences in the ERPs elicited by anomalous and nonanomalous sentences. In Experiment 1, ERPs to syntactically or semantically anomalous words diverged from the control condition beginning at about $300 \mathrm{msec}$. In Experiment 2, the semantic anomaly response had a slightly earlier onset than did the syntactic anomaly response. At first glance, such findings might seem paradoxical; by most accounts, syntactic analysis precedes semantic analysis (for a contrary view see Bever, Sanz, \& Townsend, 1998). However, recent findings suggest that semantic and pragmatic anomalies can be detected very rapidly (Fodor et al., 1996; Ni et al., 1998) and in some case semantic/ pragmatic anomalies can be overtly responded to more rapidly than syntactic anomalies (Tyler, 1985). Particularly noteworthy given the present findings is a study by $\mathrm{Ni}$ et al. (1998), who recorded eye movements during the reading of sentences that were highly similar to those presented in Experiment 1 of the current study. The syntactic and semantic anomalies were detected very rapidly and with no appreciable effect of anomaly type on the timing of the eye-movement response to the anomaly. Interestingly, however, anomaly type did have an effect on the qualitative pattern of eye movements: Semantic anomalies resulted in longer first-pass reading times, whereas syntactic anomalies induced more regressive eye movements.

Finally, we should also note that word-by-word presentation of sentences at a rate of one word every $650 \mathrm{msec}$ is far removed from the "usual" manner of reading. It could be that this mode of presentation encourages subjects to adopt "unnatural" strategies for reading sentences and that the effects observed here would not be observed under more 
"natural" conditions. However, prior work presenting sentences in the form of continuous natural speech has observed N400 and P600 effects to semantic and syntactic anomalies, respectively, that were similar to the effects reported here (Holcomb \& Neville, 1991; Osterhout \& Holcomb, 1993).

To summarise, semantic anomalies (selectional restriction violations) and syntactic anomalies (verb tense violations) elicited qualitatively distinct ERP responses (the N400 and P600 effects, respectively). Doubly anomalous words elicited both effects, and these effects summated in an approximately linear manner. These findings therefore provide additional evidence that, at least under certain experimental conditions, syntactic and semantic anomalies elicit qualitatively distinct and largely independent brain responses.

\section{REFERENCES}

Ainsworth-Darnell, K., Shulman, H., \& Boland, J.E. (1997). Dissociating brain responses to syntactic and semantic anomalies: Evidence from event-related brain potentials. Journal of Memory and Language, 36, 112-130.

Altmann, G.T.M. (1998). Ambiguity in sentence processing. Trends in Cognitive Sciences, 2, 146-152.

Berwick, R., \& Weinberg, A. (1984). The grammatical basis of linguistic performance. Cambridge, MA: MIT Press.

Bever, T., Sanz, M., \& Townsend, D.J. (1998). The emperor's psycholinguistics. Journal of Psycholinguistic Research, 27, 261-284.

Brown, C.M., \& Hagoort, P. (1993). The processing nature of the N400: Evidence from masked priming. Journal of Cognitive Neuroscience, 5, 34-44.

Chomsky, N. (1965). Aspects of the theory of syntax. Cambridge, MA: MIT Press.

Chomsky, N. (1986). Knowledge of language. New York: Praeger.

Coulson, S., King, J., \& Kutas, M. (1998). Expect the unexpected: Event-related brain responses to morphosyntactic violations. Language and Cognitive Processes, 13, 21-58.

Donchin, E. (1981). Surprise! ... Surprise? Psychophysiology, 18, 493-513.

Ferreira, F., \& Clifton, C., Jr. (1986). The independence of syntactic processing. Journal of Memory and Language, 25, 348-368.

Fodor, J.D., Ni, W., Crain, S., \& Shankweiler, D. (1996). Tasks and timing in the perception of linguistic anomaly. Journal of Psycholinguistic Research, 25, 25-57.

Fodor, J.F. (1983). Modularity of mind. Cambridge, MA: MIT Press.

Forster, K.I. (1979). Levels of processing and the structure of the language processor. In W. Cooper and E.C.T. Walker (Eds.), Sentence processing. Hillside, NJ.: Erlbaum.

Frazier, L. (1987). Sentence processing: A tutorial. In M. Coltheart (Ed.), Attention and Performance XII (pp. 559-585). Hove, UK: Lawrence Erlbaum Associates Ltd.

Frazier, L., \& Rayner, K. (1982). Making and correcting errors during sentence comprehension: Eye movements in the analysis of structurally ambiguous sentences. Cognitive Psychology, 14, 178-210.

Friederici, A.D., Hahne, A., \& Mecklinger, A. (1996). Temporal structure of syntactic processing: early and late event-related potential effects. Journal of Experimental Psychology: Learning, Memory, and Cognition, 22, 1219-1248. 
Friederici, A.D., Pfeifer, E., \& Hahne, A. (1993). Event-related brain potentials during natural speech processing: Effects of semantic, morphological and syntactic violations. Cognitive Brain Research, 1, 183-192.

Garnsey, S. (1993). Event-related brain potentials in the study of language: An introduction. Language and Cognitive Processes, 8, 337-356.

Greenhouse, S., \& Geisser, S. (1959). On methods in the analyses of profile data. Psychometrika, 24, 95-112.

Gunter, T., Stowe, L., \& Mulder, G. (1997). When syntax meets semantics. Psychophysiology, 34, 660-676.

Hagoort, P., Brown, C., \& Groothusen, J. (1993). The syntactic positive shift as an ERP measure of syntactic processing. Language and Cognitive Processes, 8, 439-483.

Holcomb, P.J. (1993). Semantic priming and stimulus degradation: Implications for the role of the N400 in language processing. Psychophysiology, 30, 47-62.

Holcomb, P.J., \& Neville, H.J. (1991). The electrophysiology of spoken sentence processing. Psychobiology, 19, 286-300.

Jasper, H.H. (1958). Report to the committee on methods of clinical examination in electroencephalography. Appendix: The ten-twenty system of the International Federation. Electroencephalography and Clinical Neurophysiology, 10, 371-375.

Johnson-Laird, P. (1983). Mental models. Cambridge, MA: Harvard University Press.

Keppel, G. (1982). Design and analysis: A researcher's handbook. Englewood Cliffs, NJ: Prentice-Hall.

Kucera, H., \& Francis, W.N. (1967). Computational analysis of present-day American English. Providence, RI: Brown University Press.

Kutas, M., \& Hillyard, S.A. (1980a). Event-related brain potentials to semantically inappropriate and surprisingly large words. Biological Psychology, 11, 99-116.

Kutas, M., \& Hillyard, S.A. (1980b). Reading between the lines: Event-related brain potentials during natural sentence processing. Brain and Language, 11, 354-373.

Kutas, M., \& Hillyard, S.A. (1980c). Reading senseless sentences: Brain potentials reflect semantic incongruity. Science, 207, 203-205.

Kutas, M., \& Hillyard, S.A. (1984). Brain potentials during reading reflect word expectancy and semantic association. Nature, 307, 161-163.

Kutas, M., Lindamood, T., \& Hillyard, S.A. (1984). Word expectancy and eventrelated brain potentials during sentence processing. In S. Kornblum \& J. Renquin (Eds.), Preparatory states and processes. Hillsdale, NJ: Lawrence Erlbaum Associates Inc.

Kutas, M., \& Van Petten, C. (1994). Psycholinguistics electrified: Event-related brain potential investigations. In M.A. Gernsbacher (Ed.), Handbook of psycholinguistics (pp. 83-143). San Diego: Academic Press.

MacDonald, M.C., Pearlmutter, N.J., \& Seidenberg, M.S. (1994). The lexical nature of ambiguity resolution. Psychological Review, 101, 676-703.

Marslen-Wilson, W.D., \& Tyler, L.K. (1987). Against modularity. In J.L. Garfield, (Ed.), Modularity in knowledge representation and natural-language understanding. Cambridge, MA: MIT Press.

McClelland, J.L., St John, M., \& Taraban, R. (1989). Sentence comprehension: A parallel distributed processing approach. Language and Cognitive Processes, 4, 287-336.

McElree, B., \& Griffith, T. (1995). Syntactic and thematic processing in sentence comprehension: Evidence for a temporal dissociation. Journal of Experimental Psychology: Learning, Memory, \& Cognition, 21, 134-157.

McKinnon, R., \& Osterhout, L. (1996). Constraints on movement phenomena in sentence processing: Evidence from event-related brain potentials. Language and Cognitive Processes, 11, 495-523. 
Münte, T.F., Heinze, H.-J., \& Mangun, G.R. (1993). Dissociation of brain activity related to syntactic and semantic aspects of language. Journal of Cognitive Neuroscience, 5, 335344.

Münte, T.F., Heinze, H.-J., Matzke, M., Wieringa, B.M., \& Johannes, S. (1998). Brain potentials and syntactic violations revisited: No evidence for the specificity of the syntactic positive shift. Neuropsychologia, 36, 217-226.

Neville, H.J., Kutas, M., Chesney, G., \& Schmidt, A.L. (1985). Event-related brain potentials during initial encoding and recognition memory of congruous and incongruous words. Journal of Memory and Language, 25, 75-92.

Neville, H.J., Mills, D.J., \& Lawson, D.S. (1992). Fractionating language: different neural subsystems with different sensitive periods. Cerebral Cortex, 2, 244-258.

Neville, H.J., Nicol, J.L., Barss, A., Forster, K.I., \& Garrett, M.F. (1991). Syntactically based processing classes: Evidence from event-related potentials. Journal of Cognitive Neuroscience, 3, 151-165.

Ni, W., Crain, S., \& Shankweiler, D. (1996). Sidestepping garden paths: Assessing the contributions of syntax, semantics, and plausibility in resolving ambiguities Language and Cognitive Processes, 11, 283-334.

Ni, W., Fodor, J.D., Crain, S., \& Shankweiler, D. (1998). Anomaly detection: Eye movement patterns. Journal of Psycholinguistic Research, 27, 515-539.

Nunez, P.L. (1981). Electrical fields in the brain: The neurophysics of EEG. New York: Oxford University Press.

Nunez, P.L. (1990). Physical principles and neurophysiological mechanisms underlying event-related potentials. In J.W. Rohrbaugh \& R. Parasuraman (Eds.), Event-related brain potentials: Basic issues and applications (pp. 1931). New York: Oxford University Press.

Nunez, P.L. (1998). Neocortical dynamics of macroscopic-scale EEG measurements. IEEE Engineering in Medicine and Biology, 17, 110-117.

Nunez, P.L., Srinivasan, R., Westdorp, A.F., Wijesinghe, R., Tucker, D.M., Silberstein, R.B., \& Cadusch, P.J. (1997). EEG coherency: I. Statistics, reference electrode, volume conduction, Laplacian, cortical imaging, and interpretation of multiple scales. Electroencephalography and Clinical Neurophysiology, 103, 499-515.

Osterhout, L. (1990). Event-related brain potentials elicited during sentence comprehension. Unpublished doctoral dissertation, Tufts University.

Osterhout, L. (1994). Event-related brain potentials as tools for comprehending language comprehension. In C. Clifton, Jr., L. Frazier, \& K. Rayner, (Eds.), Perspectives on sentence processing. Hillsdale, NJ: Lawrence Erlbaum Associates Inc.

Osterhout, L. (1997). On the brain response to syntactic anomalies: Manipulations of word position and word class reveal individual differences. Brain and Language, 59, 494-522.

Osterhout, L., Bersick, M., \& McLaughlin, J. (1997). Brain potentials reflect violations of gender stereotypes. Memory and Cognition, 25, 273-285.

Osterhout, L., \& Hagoort, P. (1999). A superficial resemblance does not necessarily mean that you are part of the family: Counterarguments to Coulson, King, and Kutas (1998) in the P600/SPS-P300 debate. Language and Cognitive Processes, 14, 1-14.

Osterhout, L., \& Holcomb, P.J. (1992). Event-related brain potentials, elicited by syntactic anomaly. Journal of Memory and Language, 31, 785-806.

Osterhout, L., \& Holcomb, P.J. (1993). Event-related potentials and syntactic anomaly: Evidence of anomaly detection during the perception of continuous speech. Language and Cognitive Processes, 8, 413-438.

Osterhout, L., \& Holcomb, P.J. (1995). Event-related brain potentials and language comprehension. In M.D. Rugg \& M.G.H. Coles (Eds.), Electrophysiology of mind: Event-related brain potentials and cognition. Oxford: Oxford University Press. 
Osterhout, L., Holcomb, P.J., \& Swinney, D.A. (1994). Brain potentials elicited by gardenpath sentences: Evidence of the application of verb information during parsing. Journal of Experiment Psychology: Learning, Memory, \& Cognition, 20, 786-803.

Osterhout, L., McKinnon, R., Bersick, M., \& Corey, V. (1996). On the language-specificity of the brain response to syntactic anomalies: Is the syntactic positive shift a member of the P300 family? Journal of Cognitive Neuroscience, 8, 507-526.

Osterhout, L., McLaughlin, J., \& Bersick, M. (1997). Event-related brain potentials and human language. Trends in Cognitive Sciences, 1, 203-209.

Osterhout, L., \& Mobley, L.A. (1995). Event-related brain potentials elicited by failure to agree. Journal of Memory and Language, 34, 739-773.

Rayner, K., Carlson, M., \& Frazier, L. (1983). The interaction of syntax and semantics during sentence processing. Journal of Verbal Learning and Verbal Behavior, 22, 358-374.

Rösler, F., Pütz, P., Friederici, A., \& Hahne, A. (1993). Event-related brain potentials while encountering semantic and syntactic constraint violations. Journal of Cognitive Neuroscience, 5, 345-362.

Rugg, M.D., \& Coles, M.G.H. (1995). The ERP and cognitive psychology: Conceptual issues. In M.D. Rugg \& M.G.H. Coles (Eds.), Electrophysiology of mind: Event-related brain potentials and cognition. Oxford: Oxford University Press.

Taraban, R., \& McClelland, J. (1988). Constituent attachment and thematic role assignment in sentence processing: Influences of content-based expectations. Journal of Memory and Language, 27, 597-632.

Trueswell, J.C., Tanenhaus, M.K., \& Garnsey, S.M. (1994). Semantic influences on parsing: Using thematic role information in syntactic ambiguity resolution. Journal of Memory and Language, 33, 285-318.

Tyler, L.K. (1985). Real-time comprehension processes in agrammatism: A case study. Brain and Language, 26, 259-275.

Tyler, L.K., \& Marslen-Wilson, W.D. (1977). The on-line effects of semantic context on syntactic processing. Journal of Verbal Learning and Verbal Behavior, 16, 683-692.

\section{APPENDIX}

Experimental Sentences Presented in Experiment 1. Three Versions of each Sentence were Constructed: Nonanomalous, Syntactically Anomalous (Verb Tense Violations), and Semantically Anomalous (Selectional Restriction Violations).

The cats won't eat/eating/bake the food that Mary gives them.

The astronomer's argument might prove/proving/shout that there are three canals on the moon.

In case of a break-in, the alarm system will warn/warning/swear that there is an intruder.

The new species of orchid will grow/growing/sing in tropical regions.

This expensive ointment will cure/curing/loathe all known forms of skin disease.

This old electric blender doesn't crush/crushing/own ice cubes anymore.

This exotic spice may add/adding/seek the oriental flavour that John enjoys.

The new fighter plane can fly/flying/walk faster than anyone had expected.

The boxes in the attic may still hold/holding/find many old photographs and souvenirs.

This test of reasoning might fail/failing/hate to discriminate among students.

The puppy seems to like/liking/call/calling to sleep a lot during the day.

The cowboy always gives his horse a chance to drink/drinking/fish from the stream.

Billy bumped his bicycle, causing it to fall/falling/sneeze into the street.

The therapist hoped that the new drug would calm/calming/clean the patient who was so anxious. 
The new software package will print/printing/glue very elaborate pictures.

The publisher hoped that the textbook would draw/drawing/hear students with a variety of interests.

William thought that he would fitfitting/dig right in with the crowd at the reception.

Mary knew that the food at the hotel would cost/costing/fight too much.

The hikers noticed that the boulder seemed to rest/resting/live precariously on the mountain. At the aquarium, there are otters that swim/swimming/fly and do tricks for the crowds.

Every day at three, the newspapers should land/landing/dance on the porch out front.

The tree in the backyard can't sprout/sprouting/sell new buds in this weather.

Most physicians believe that the new drugs can prevent/preventing/study many forms of disease.

The composer agreed that his music should enchant/enchanting/question the public.

The repairman thinks that the leaky tub might bother/bothering/ask the tenants downstairs.

This rare herb can heal/healing/count the pains in your back.

The farmhouse is so old that it scares/scaring/writes the neighbours.

The teacher said our report must not last/lasting/cry for more than ten minutes.

In the nation's landfills, chemicals of different sorts may mix/mixing/hope to create lethal substances.

The simulated accident might frighten/frightening/ignore the children enough so that they will wear their bike helmets.

The plumber said that the leaking water might seep/seeping/speak out from behind the refrigerator.

The fingerprints on the gun could prove/proving/judge that the defendant is innocent.

The beavers in the pond sometimes chew/chewing/melt the garden hose.

The fancy French clock doesn't tell/telling/ask the time during power failures.

Critics say that the rap songs might tend/tending/learn to lead young people astray.

The new brand of toothpaste could help/helping/beg to provide protection against disease.

Those small spiders would often spin/spinning/burn beautiful webs.

The pacifier we bought in Japan will soothe/soothing/drop the cranky baby.

The skyscraper being built by the city would block/blocking/send out the sunlight.

These grapevines don't grow/growing/jog well in sandy regions.

At the end of the day, the dog always waits/waiting/peaks in the driveway.

We hoped that the news of the award would cheer/cheering/wash up the depressed student.

The circus elephants get on their hind legs and stand/standing/chirp, which impresses the audience.

Simple vegetable oil is used to fry/frying/plow the vegetables.

The black widow spider likes to hide/hiding/sigh in dark places.

Fountain pens shouldn't be used to sketch/sketching/dust since they were designed only for writing.

It was hard to get the infant to smile/smiling/vote for the photographer.

The defendant's account of the incident didn't match/matching/paste the one given by the codefendant.

The movers didn't think that the piano would weigh/weighing/cough as much as it did.

Susan was worried that her kitten would scratch/scratching/lift the young child.

The peregrine falcon chicks always chirp/chirping/staple until the father brings food.

The general admits that the missile might explode/exploding/call before leaving the area.

The assistant was told that the alibi would prevent/preventing/consider an indictment.

My grandfather's habit of chasing geese might shock/shocking/stab you, but he's quite normal otherwise.

People hope that the sculpture will inspire/inspiring/invent new forms of artistic expression. So many bugs live in the garden, they must eat/eating/buy a head of lettuce every minute. 
The booklet says that the contraceptive will fail/failing/complain if used too sparingly. My brother bet that this spider could climb/climbing/type faster than you could.

The baby's teeth are so sore that the pacifier might hurt/hurting/cheat her too much.

The supervisor's report found that the factory should train/training/hug workers more thoroughly.

One kangaroo at the San Diego Zoo would sometimes sit/sitting/write all day.

The portrait of Uncle Henry doesn't look/looking/sing like him.

The new heater in the maid's room should dry/drying/find the laundry.

The strawberry beds might tempt/tempting/sneeze rabbits and other animals.

The colours in the sweater should not fade/fading/walk when the sweater is washed.

The new chemical additive may tend/tending/desire to lower the freezing point of water.

The sea lions can bask/basking/edit on the beach all day.

The security camera at the bank will now take/taking/trip photographs of everyone.

The bull that escaped could smash/smashing/send the wooden fence around the meadow.

The award winning play will run/running/leap for several more months.

The couple's newborn baby sneezes/sneezing/types so much that they took her to the doctor.

The hiker used his last match to start/starting/tie the fire.

Where the road forks/forking/believes, we couldn't figure out which way to go.

Bob's rubber raft hit/hitting/loves a rock, which punctured it.

After Jane's accident, she found it difficult to drive/driving/boil for several months.

The pet cats will soon eat/eating/describe their evening meal.

The raging bull will charge/charging/whistle at the man.

The new romance novel should sell/selling/leak in every store this year.

Alison used a hammer to break/breaking/kiss the small lock.

Betsy went out to the orchard to pick/picking/melt apples for a pie.

The powerful magnet will pull/pulling/learn defective parts from the assembly line.

The lever on the basement wall does not shut/shutting/lift off the power supply.

The new detergent is supposed to clean/cleaning/burn the floors with ease.

The newly planted grass will grow/growing/swim quite a bit during the next year.

The hidden door will open/opening/cook when the secret code is spoken.

A new computer will last/lasting/paint for many years.

The local beers in Seattle will satisfy/satisfying/trip every beer drinker.

The red ants in Arizona will bite/biting/wash you if you are not careful.

The new crop of corn should feed/feeding/scrape everyone in the state.

The noisy ducks will soon fly/flying/skip away from the lake. 